From dysfunctional endoplasmic reticulum-mitochondria coupling to neurodegeneration

Zoi Erpapazoglou ${ }^{1-4}$, François Mouton-Liger ${ }^{1-4}$, and Olga Corti ${ }^{1-4, *}$

${ }^{1}$ Inserm, U1127, F-75013, Paris, France

${ }^{2}$ CNRS, UMR 7225, F-75013, Paris, France

${ }^{3}$ Sorbonne Universités, UPMC Univ Paris 06, UMR S 1127, F-75013, Paris, France

${ }^{4}$ Institut du Cerveau et de la Moelle épinière, ICM, F-75013, Paris, France

*corresponding author: olga.corti@upmc.fr, +33157274651 


\section{Abstract}

Over the last years, contact sites between the endoplasmic reticulum (ER) and mitochondria have attracted great attention in the study of cell homeostasis and dysfunction, especially in the context of neurodegenerative disorders. This is largely due to the critical involvement of this subcellular compartment in a plethora of vital cellular functions: $\mathrm{Ca}^{2+}$ homeostasis, mitochondrial dynamics, transport, bioenergetics and turnover, ER stress, apoptotic signaling and inflammation. An increasing number of disease-associated proteins have been reported to physically associate with the ERmitochondria interface, and cause structural and/or functional perturbations of this compartment. In the present review, we summarize current knowledge about the architecture and functions of the ER-mitochondria contact sites, and the consequences of their alteration in different neurodegenerative disorders. Special emphasis is placed on the caveats and difficulties in defining the nature and origin of the highlighted defects in ER-mitochondria communication, and their exact contribution to the neurodegenerative process.

Keywords: ER-mitochondria contacts, neurodegeneration, calcium and lipid metabolism, inflammation, Alzheimer's disease, Parkinson's disease, Amyotrophic Lateral Sclerosis 
1. Introduction . .4

2. Multifaceted regulation of cellular physiology by the ER-mitochondria interface 4

2.1 Key moments in the study of ER-mitochondria contact sites . .4

2.2 ER-mitochondria contacts as hubs regulating membrane dynamics, signaling and cell death mechanisms . .7

3. Defects in ER-mitochondria communication in neurodegenerative diseases ... . .8

3.1 Alzheimer's disease . .9

3.2 Parkinson's disease 10

3.3 Amyotrophic Lateral Sclerosis .12

4. ER-mitochondria contact sites in neuroinflammation 13

5. Caveats and difficulties in assessing the structure and function of the ER-mitochondria interface 15

6. Conclusions .18 


\section{Introduction}

Neurodegeneration is a pathological condition due to the progressive and irreversible dysfunction and loss of neurons and synapses at selected areas of the nervous system. Depending on which region is affected, the clinical presentation and course of the pathology differs, explaining the vast spectrum of known neurodegenerative disorders: Alzheimer's disease (AD), Parkinson's disease (PD), fronto-temporal dementia (FTD), amyotrophic lateral sclerosis (ALS), Huntington's disease (HD), hereditary spastic paraplegia (HSP), Charcot Marie Tooth (CMT). Common pathogenic mechanisms have been described for these diseases, including abnormal proteostasis, often associated with the formation of intracellular and/or extracellular protein inclusions, ER and oxidative stress, mitochondrial dysfunction, and neuroinflammation (Jellinger, 2010).

In the present review, we discuss the role of the ER-mitochondria interface in the maintenance of cellular homeostasis and summarize recent literature reporting defects in ER-mitochondria communication in different neurodegenerative disorders. We emphasize current limitations in studying this subcellular compartment and its regulators, and in defining its exact contribution to the process of neurodegeneration.

\section{Multifaceted regulation of cellular physiology by the ER-mitochondria interface}

\subsection{Key moments in the study of ER-mitochondria contact sites}

Sites of close apposition between the ER and mitochondria were initially observed on tissue electron micrographs in the late 50's (Copeland and Dalton, 1959). However, it is only in the 90's that we obtained insight into the biological significance of these contact sites. First, subcellular fractionation led to the isolation of a mitochondria-associated membrane fraction, referred to in subsequent studies as the MAM, containing the enzymatic activities involved in the biosynthesis of serinecontaining phospholipids and lipid transfer between ER and mitochondria (Vance, 1990). Phosphatidylserine (PS) is produced at the ER by the PS synthase, and then shuttled into the inner mitochondrial (IM) membrane where it is converted by PS decarboxylase into phosphatidylethanolamine $(\mathrm{PE})$. $\mathrm{PE}$ is then retranslocated to the $E R$ and methylated into phosphatidylcholine (PC), the most abundant membrane lipid, by $N$-methyltransferase-2 (reviewed in (Vance, 2014), Figure 1). In a similar manner, biosynthesis of the mitochondria-specific lipid cardiolipin (CL) and metabolism of cholesterol, the major component of lipid rafts, rely on enzymatic activities of both the ER and the mitochondrion, as well as shuttling of substrates between the two membranes.

$\mathrm{Ca}^{2+}$ imaging approaches revealed a second fundamental function of ER-mitochondria contacts: microdomains with high $\mathrm{Ca}^{2+}$ concentration form in the vicinity of mitochondria upon stimulation of $E R \mathrm{Ca}^{2+}$ release by $1,3,4$ inositol triphosphate receptors ( $\left(\mathrm{P}_{3} \mathrm{Rs}\right)$, and play a central role in $\mathrm{Ca}^{2+}$ uptake 
into the mitochondrial matrix (Rizzuto et al., 1993; Rizzuto et al., 1998). Further studies confirmed that $\mathrm{Ca}^{2+}$-releasing channels of the ER (IP ${ }_{3} \mathrm{Rs}$, ryanodine receptors-RyRs) are enriched at contact sites (Garcia-Perez et al., 2008; Szabadkai et al., 2006). Upon stimulation, they transiently increase cytosolic $\mathrm{Ca}^{2+}$ concentration on the mitochondrial surface at levels compatible with efficient diffusion across voltage-dependent anion channels (VDACs) at the outer mitochondrial (OM) membrane (Rapizzi et al., 2002), and subsequent uptake by the low-affinity mitochondrial calcium uniporter (MCU), juxtaposed at the IM membrane ((Baughman et al., 2011; De Stefani et al., 2011), Figure 1). The chaperone glucose-regulated protein 75 (GRP75) bridges $\mathrm{IP}_{3} \mathrm{R}$ and VDAC at ER-mitochondria contact sites; this tripartite complex ensures the coupling of $\mathrm{Ca}^{2+}$ release from the $\mathrm{ER}$ with $\mathrm{Ca}^{2+}$ import into the mitochondrial matrix (Szabadkai et al., 2006), and most likely keeps ER and mitochondria at the appropriate distance for efficient $\mathrm{Ca}^{2+}$ diffusion (Csordas et al., 2006; Csordas et al., 2010; Giacomello and Pellegrini, 2016).

Molecular chaperones at the ER, as well as the mitochondrial ATP synthase and the dehydrogenases that provide reducing equivalents to the respiratory chain, depend on $\mathrm{Ca}^{2+}$ concentration for efficient enzymatic activity. Hence, ER-to-mitochondria $\mathrm{Ca}^{2+}$ transfers are key determinants of ER folding capacity and mitochondrial metabolism (Cardenas et al., 2010; Simmen et al., 2010). Enhancement of these fluxes allows coping with an increased energy demand (Betz et al., 2013; Bravo et al., 2011), but an excess of these transfers initiates programmed cell death, as it will be discussed in the next section. The importance of mitochondrial $\mathrm{Ca}^{2+}$ uptake in cellular homeostasis is highlighted by the severity of the phenotypes associated with MCU dysfunction. In humans, mutations in the gene coding for the $\mathrm{Ca}^{2+}$-sensitive MCU regulator MICU1 (mitochondrial calcium uptake 1 ) cause a multisystem disorder associated with myopathy and neurological symptoms (Logan et al., 2014). MCU silencing led to gastrulation defects in zebrafish (Prudent et al., 2013) and growth and infectivity defects in trypanosomes (Huang et al., 2013). Surprisingly, however, MCU KO mice presented with milder phenotypes, showing no major developmental defects and normal viability on a mixed CD1/C57BL/6 genetic background (Murphy et al., 2014; Pan et al., 2013). Though mitochondrial $\mathrm{Ca}^{2+}$ uptake was strongly impaired in tissue and cells from these mice, basal respiration and cell death triggered by different stress conditions were not significantly altered (Pan et al., 2013). However, knockout of the MCU was embryonic lethal on a pure C57BL/6 strain (Murphy et al., 2014), suggesting the existence of yet unidentified compensatory mechanisms, depending on the genetic background.

Altogether, despite the multitude of biological processes in which ER-mitochondria contacts have been implicated over the last years, measurement of lipid biosynthesis and $\mathrm{Ca}^{2+}$ exchanges between the two organelles have become the gold-standard functional read-outs for the assessment of the integrity of this subcellular compartment. 
Electron microscopy studies contributed majorly in unravelling the structural diversity and plasticity of ER-mitochondria contact sites. In these studies, mitochondria were found in proximity to both smooth and rough ER tubules, with an interorganellar distance ranging between 10 and $80 \mathrm{~nm}$ (Copeland and Dalton, 1959; Csordas et al., 2006; Giacomello and Pellegrini, 2016; Sood et al., 2014). The length of the contact zone is highly variable and may reach several hundreds of $\mathrm{nm}$. 3D reconstitution of ER-mitochondria contact sites by focused ion beam scanning electron microscopy (FIB-SEM) demonstrated that each mitochondrion may engage in multiple contacts with the ER, which are highly diverse in length (Krols et al., 2016). Apoptotic stimuli (Csordas et al., 2006), ER stress (Bravo et al., 2011) or metabolic state (Sood et al., 2014), affect the number, length and/or width (interorganellar distance) of contact sites. This architectural complexity and plasticity emanates greatly from the biochemical properties of the ER-mitochondria interface, determined by its lipid and protein composition (Area-Gomez, 2014; Raturi and Simmen, 2013). A growing list of proteins has been shown to be enriched in the MAM fraction of cell lysates or tissue homogenates. Membranes in the MAM fraction display composition and properties similar to lipid rafts (AreaGomez et al., 2012). This lipid raft nature is believed to play key roles in protein recruitment and activation of biological pathways within the MAM fraction.

The visualization by electron tomography of protein complexes at sites of contact (Csordas et al., 2006) raised the question of the identity of the molecular machineries that tether the ER to the OM membrane. In yeast, a genetic screen based on rescue of respiratory-deficient mutants by an artificial ER-mitochondria tether, identified the ER-Mitochondria Encounter Structure (ERMES), a complex of ER (Mmm1), cytosolic (Mdm12) and OM membrane proteins (Mdm10 and Mdm34), required for proper phospholipid biosynthesis between the two organelles (Kornmann et al., 2009). In mammals, the identity of the ER-mitochondria tethering complexes remains elusive. There is a consensus that mitofusin 2 ( $\mathrm{Mfn} 2$ ) localizes both on the ER and OM membranes and regulates ER-mitochondria juxtaposition, although whether it functions as a tether (Alford et al., 2012; de Brito and Scorrano, 2008; Naon et al., 2016; Schneeberger et al., 2013) or tethering inhibitor (Cosson et al., 2012; Filadi et al., 2015, 2016; Leal et al., 2016) has been discussed. Controversial observations are not limited to the above mentioned studies, in which the role of Mfn2 in ER-mitochondria tethering was directly addressed by knockdown or knockout approaches in different model systems. They also apply to studies in which the degree of ER-mitochondria juxtaposition was correlated with endogenous Mfn2 levels: Mfn2 abundance was found to be either higher (Arruda et al., 2014; Gautier et al., 2016) or lower (Zheng et al., 2017) in models associated with an exacerbated ER-mitochondria interface. Similar discrepancies were observed when Mfn2 levels were modulated to suppress phenotypes caused by alterations in ER-mitochondria communication. Thus, Mfn2 silencing restored defects in models with either decreased (Wang et al., 2015) or increased ER-mitochondria coupling (Area- 
Gomez et al., 2012; Celardo et al., 2016; Gautier et al., 2016). We will discuss possible explanations for these recurrent controversies in section 5 .

The modulation of the expression of different proteins localized at the ER-mitochondria interface, such as phosphofurin acidic cluster sorting protein-2 (PACS-2, (Simmen et al., 2005)) and GRP75 (Szabadkai et al., 2006), was shown to affect organelle proximity. However, whether these proteins are directly involved in the tethering of the two membranes remains unclear. Recent studies have highlighted such a direct role for a complex between Vesicle-associated membrane proteinassociated protein $\mathrm{B}$ (VAPB) at the ER and protein tyrosine phosphatase-interacting protein 51 (PTPIP51) at the OM membrane (De Vos et al., 2012). In this case, expression of an artificial tether rescued the defects in ER-mitochondria communication caused by the disruption of this interorganellar complex, mediated by RNA interference (Gomez-Suaga et al., 2017).

\subsection{ER-mitochondria contacts as hubs regulating membrane dynamics, signaling and}

\section{cell death mechanisms}

Beyond lipid biosynthesis and $\mathrm{Ca}^{2+}$ transfers, ER-mitochondria contact sites play a key role in mitochondrial dynamics. Mitochondrial adaptors involved in the recruitment of the fission-promoting dynamin-related protein Drp1 (syntaxin 17, Mff, MiD49 and MiD51) localize at the ER-mitochondria interface (Arasaki et al., 2015; Elgass et al., 2015), and ER tubules surround mitochondria at sites where mitochondrial division will occur, mediating constriction prior to fission ((Friedman et al., 2011), Figure 1). Recently, ER-mitochondria contact sites were spatially linked to actively replicating mitochondrial nucleoids, suggesting that they coordinate mtDNA synthesis with mitochondrial division for the proper distribution of nucleoids into the daughter mitochondria (Lewis et al., 2016; Murley et al., 2013). In yeast, ERMES interacts genetically with the mitochondrial contact site and cristae organizing system (MICOS), a large protein complex of the IM membrane with a critical role in cristae architecture (Hoppins et al., 2011). There is a functional overlap between ERMES and MICOS in phospholipid biosynthesis, $\mathrm{Ca}^{2+}$ transfers between ER and mitochondria, mtDNA distribution and import of proteins into mitochondria (van der Laan et al., 2016). Moreover, metabolic shift triggers parallel remodeling of ER-mitochondria contacts and cristae in mouse liver (Sood et al., 2014). These findings emphasize that the ER-mitochondria interface is actually a three-membrane-spanning network, connecting the ER to the OM and IM membranes.

ER-mitochondria contact sites are also involved in the regulation of mitochondrial retrograde and anterograde transport along microtubules. Mitochondria move at maximal velocity at resting cytosolic $\mathrm{Ca}^{2+}$ concentrations, and are stalled in proximity of $\mathrm{IP}_{3} \mathrm{R}$-dependent $\mathrm{Ca}^{2+}$ hotspots, where they buffer the liberated $\mathrm{Ca}^{2+}$ (Yi et al., 2004). The $\mathrm{Ca}^{2+}$-sensitive GTPase Miro, a kinesin and dynein 
adaptor, fine tunes mitochondrial motility by inhibiting mitochondrial transport and stimulating Drp1-mediated fission at sites of high $\mathrm{Ca}^{2+}$ concentration (Saotome et al., 2008).

Other studies have linked the ER-mitochondria interface to autophagy. Upon induction of autophagy by starvation in mammalian cells, the autophagic proteins ATG14 and ATG5 are recruited at ERmitochondria contact sites to initiate formation of the phagophore (Figure 1); disruption of ERmitochondria coupling, by Mfn2 or PACS-2 down-regulation, impairs the process (Hailey et al., 2010; Hamasaki et al., 2013). On the other hand, inhibition of $\mathrm{IP}_{3} \mathrm{R}$-mediated $\mathrm{Ca}^{2+}$ transfers caused by the disruption of the VAPB-PTPIP51 tether promotes autophagy under basal conditions, or following treatment with rapamycin or Torin-1 (Gomez-Suaga et al., 2017). ERMES function is also required for efficient mitophagy in yeast (Belgareh-Touze et al., 2016; Bockler and Westermann, 2014). Mitophagosome biogenesis takes place at contact sites between ER and mitochondria both in yeast and mammals (Bockler and Westermann, 2014; Yang and Yang, 2013).

Finally, the ER-mitochondria interface serves as a niche for apoptotic signaling. Excessive $I_{3} R-$ mediated $\mathrm{Ca}^{2+}$ release leads to mitochondrial $\mathrm{Ca}^{2+}$ overload, opening of the mitochondrial permeability transition pore (mPTP), cytochrome $\mathrm{c}$ release, caspase activation and apoptosis (Vervliet et al., 2016). Members of the anti-apoptotic protein family Bcl-2 were shown to localize at ERmitochondria contacts and modulate $\mathrm{IP}_{3} \mathrm{R}$-mediated mitochondrial $\mathrm{Ca}^{2+}$ transients (Chen et al., 2004; Meunier and Hayashi, 2010; Vervliet et al., 2016; Yang et al., 2016). Regulators of caspase-8 activation were also found at the ER-mitochondria interface (Iwasawa et al., 2011; Marini et al., 2015). Resident proteins of ER-mitochondria contacts were shown to mediate the onset of apoptosis (Bui et al., 2010; Giorgi et al., 2010; Simmen et al., 2005; Verfaillie et al., 2012). For example, PACS-2 was required for the mitochondrial recruitment of the pro-apoptotic protein Bid and the activation of capsase-3, in response to apoptotic stimuli (Simmen et al., 2005). Moreover, PKR-like ER kinase (PERK), a key effector of the Unfolded Protein Response (UPR), associated constitutively with ERmitochondria contacts and was required for proper coupling of the two organelles and ROS-induced apoptosis (Verfaillie et al., 2012).

In conclusion, ER-mitochondria contact sites constitute subcellular platforms for the compartmentalization and orchestration of a plethora of cellular processes (Figure 1). Defects in, or exacerbation of the functions of this interface are expected to be detrimental for cell metabolism and survival. Moreover, perturbations of the ER-mitochondria interface can affect the function of immune cells, as it will be discussed in section 4 .

\section{Defects in ER-mitochondria communication in neurodegenerative diseases}

Over the last decade, contact sites between ER and mitochondria have attracted great attention in the field of neurodegenerative diseases, mainly because of their broad involvement in processes of 
crucial relevance to mitochondrial physiology and cell survival, as discussed in the previous paragraph. Several disease-related proteins associate transiently or constitutively with the ERmitochondria interface. Their modulation or alteration by disease-causing mutations has been shown to alter the structural and functional features of this subcellular compartment (Table 1). In the following sections, we will focus on representative examples of altered ER-mitochondria communication in the context of AD, PD and ALS.

\subsection{Alzheimer's disease}

First evidence for a link between ER-mitochondria contacts and neurodegeneration emerged from the study of $A D . A D$ is the most frequent neurodegenerative disorder, characterized by progressive loss of episodic memory and cognitive and behavioral impairment. It is caused by degeneration of hippocampal and cortical neurons and associated with the presence of intracellular tangles of hyperphorsphorylated tau and extracellular plaques of $\beta$-amyloid $(A \beta)$ peptides. Familial cases of $A D$ are rare (1\%) and are due to mutations in the genes coding for the amyloid precursor protein (APP), or for presenilins (PS1 and PS2), aspartyl proteases of the $\gamma$-secretase complex, involved in APP processing and $A \beta$ formation (Naj et al., 2017).

Both presenilins were found to be highly enriched in the MAM fraction of the ER (Area-Gomez et al., 2009). Since then, the cross-talk between ER-mitochondria communication and $A D$ has been reinforced by several additional observations. First, pathogenic mutations of PS2 have been associated with increased ER-mitochondria juxtaposition and enhanced ER-to-mitochondria $\mathrm{Ca}^{2+}$ transfers or phospholipid and cholesteryl ester biosynthesis, in different cellular models (Area-Gomez et al., 2012; Filadi et al., 2016; Zampese et al., 2011); similar changes in ER-mitochondria proximity and lipid metabolism were observed in cells from patients with mutations in PS1 or APP and with sporadic AD (Area-Gomez et al., 2012). Second, the MAM fraction of the ER was shown to be the main compartment of $\gamma$-secretase activity (Area-Gomez et al., 2012) and A $\beta$ production (Schreiner et al., 2015), and changes in ER-mitochondria coupling affect APP processing (Area-Gomez et al., 2012; Leal et al., 2016). Third, exposure of primary hippocampal neurons to nanomolar concentrations of oligomeric $A \beta$ increased ER-mitochondria proximity and $\mathrm{Ca}^{2+}$ exchanges between the two organelles (Hedskog et al., 2013). Fourth, the expression of different MAM-resident proteins (PS synthase 1, PACS-2, Sigma-1 receptor-Sigma1-R) was found to be altered in the cortex of a mouse model of AD and of AD patients postmortem, compared to control tissue (Hedskog et al., 2013). Finally, biosynthesis of phospholipids and cholesteryl esters was enhanced in human fibroblasts and mouse hippocampal neurons following exposure to the isotype 4 of apolipoprotein $E$ (ApoE4), associated with a 4- to 12-fold increase in risk for AD depending on gene dosage (Tambini et al., 2016). 
Though these findings suggest that upregulated ER-mitochondria communication is a hallmark of both sporadic and familial AD, discrepancies across studies exist concerning the role of presenilins in this compartment under normal conditions. First, expression of a disease-related mutant of PS1 or down-regulation of endogenous PS1 by RNA interference had no significant effect on ERmitochondria communication in neuroblastoma cells (Zampese et al., 2011). On the contrary, MEFs from PS1 KO mice showed up-regulation of ER-mitochondria cross-talk and phospholipid biosynthesis (Area-Gomez et al., 2012). Second, down-regulation of PS2 by RNA interference in neuroblastoma cells led to a decrease in ER-mitochondria juxtaposition and $\mathrm{Ca}^{2+}$ exchanges compared to control cells (Zampese et al., 2011). The opposite effect was observed in MEFs from PS2 knock-out mice, where ER-mitochondria coupling and phospholipid biosynthesis were increased compared to MEFs from wild-type mice (Area-Gomez et al., 2012).

\subsection{Parkinson's disease}

$\mathrm{PD}$ is the second most common neurodegenerative disease and the most frequent motor disorder. It is due to the progressive degeneration of the dopaminergic neurons of the substantia nigra pars compacta, and is often characterized by the presence of intracellular protein inclusions mainly composed of $\alpha$-synuclein, the Lewy bodies. Approximately $10 \%$ of the cases are due to monogenic mutations (Hernandez et al., 2016). Physical and/or functional association with ER-mitochondria contacts was demonstrated in the case of the PD-related proteins $\alpha$-synuclein (Cali et al., 2012; Guardia-Laguarta et al., 2014), DJ-1 (Ottolini et al., 2013), PINK1 (Celardo et al., 2016; Gelmetti et al., 2017) and Parkin (Cali et al., 2013; Celardo et al., 2016; Gautier et al., 2016; Gelmetti et al., 2017; Van Laar et al., 2015; Zheng et al., 2017).

Missense mutations or whole-locus multiplications of the $\alpha$-synuclein gene cause autosomal dominant parkinsonism. $\alpha$-Synuclein was shown to be enriched in the MAM fraction of the ER in cell lines and mouse and human brain (Guardia-Laguarta et al., 2014). Pathogenic mutations weakened the association of the protein with the MAM fraction, and caused its redistribution to mitochondria and/or cytosol. They also decreased ER-mitochondria juxtaposition and production of phospholipids. Similar effects on ER-mitochondria communication, translated into reduced ER-to-mitochondria $\mathrm{Ca}^{2+}$ transients, were observed in a paradigm of $\alpha$-synuclein overexpression and aggregation in cytosolic foci in cell lines (Cali et al., 2012).

Mutations in the PARK2 gene, coding for the cytosolic E3 ubiquitin protein ligase Parkin, are the main cause of autosomal recessive PD. In cooperation with the PD-related mitochondrial Ser/Thr kinase PINK1, encoded by the PARK6 gene, Parkin orchestrates a quality control pathway that regulates multiple aspects of mitochondrial physiology: fission, transport, biogenesis, respiration and turnover by mitophagy (Corti and Brice, 2013; Pickrell and Youle, 2015). PINK1/Parkin-dependent autophagic 
turnover of damaged mitochondria has been thoroughly characterized, and ER-mitochondria contact sites were shown to constitute initiation sites for this process (Yang and Yang, 2013). Parkin was shown to be enriched in the MAM fraction of neurons exposed to glutamate excitotoxicity (Van Laar et al., 2015) and cell lines, upon induction of mitophagy (Gelmetti et al. 2017), and to ubiquitylate several proteins of the ER-mitochondria interface, including Mfn2, VDACs and Miro (Pickrell and Youle, 2015; Sarraf et al., 2013). PINK1 was also found in the MAM fraction during mitophagy (Gelmetti et al. 2017). Together with the pro-autophagic protein Beclin1, it increased ERmitochondria juxtaposition and promoted autophagosome formation.

Four independent studies reported a role of Parkin in the regulation of the ER-mitochondria interface. In the first one, Cali et al. showed that overexpression of Parkin in neuroblastoma cells increases ER-mitochondria juxtaposition, and enhances $\mathrm{IP}_{3} \mathrm{R}$-dependent mitochondrial $\mathrm{Ca}^{2+}$ transients and ATP production; Parkin down-regulation by RNA interference has the opposite effect (Cali et al., 2013). Parkin overexpression in nigral neurons also led to a slight increase in the percentage of mitochondria in contact with the ER (Zheng et al., 2017). In contrast, we and others recently associated Parkin and PINK1 dysfunction with an exacerbation of the ER-mitochondria interface (Celardo et al., 2016; Gautier et al., 2016). In particular, ER-mitochondria juxtaposition was found to be increased in fibroblasts from patients with PARK2 or PARK6 mutations compared to cells from healthy donors (Celardo et al., 2016; Gautier et al., 2016). Similar structural alterations were observed in MEFs from PARK2 knock-out mice (Gautier et al., 2016) and brain tissue from pink1 and parkin flies (Celardo et al., 2016). In fibroblasts from patients with PARK2 mutations, this alteration was associated with higher mitochondrial $\mathrm{Ca}^{2+}$ absorption than in control cells, upon $\mathrm{PP}_{3} \mathrm{R}$ stimulation (Gautier et al., 2016). We and Celardo et al. attributed this defect to the Parkin substrate Mfn2. Parkin dysfunction increased Mfn2 abundance specifically at the MAM fraction, and down-regulation of $\mathrm{Mfn} 2$ restored $\mathrm{Ca}^{2+}$ fluxes at normal levels in cells with PARK2 mutations (Gautier et al., 2016) or protected pink1 and parkin flies against ER stress (Celardo et al., 2016). Of note, Parkin has recently been reported to co-regulate ER-mitochondria juxtaposition together with the transcription factor peroxisome proliferator-activated receptor $\gamma$ coactivator $1 \alpha$ (PGC1 $\alpha$ ), a key modulator of mitochondrial biogenesis (Zheng et al., 2017). In this study, the overexpression of PGC1 $\alpha$ in the mouse substantia nigra by means of an adeno-associated viral vector led to exacerbation of ERmitochondria contacts that was suppressed by the co-expression of Parkin. PGC1 $\alpha$ overexpression was found to promote the proteasome-dependent degradation of Mfn2 and exogenous Parkin did not further impact this process. These results suggest that Mfn2 acts as an antagonist of ERmitochondria tethering in this model, but that it does not mediate the interplay between Parkin and PGC1 $\alpha$ on the degree of tethering. 
So far, familial PD has been associated with either down-regulation or up-regulation of the functions of the ER-mitochondria interface. Future studies will have to determine whether the differential effect of PD-related mutations on ER-mitochondria communication reflects the induction of distinct mechanisms leading to neurodegeneration, or whether it corresponds to different stages of the same process.

\subsection{Amyotrophic Lateral Sclerosis}

ALS is the most frequent motor neuron syndrome, characterized by progressive muscle atrophy leading to paralysis, and ultimately death. It is due to motor neuron loss in the spinal cord, motor cortex and brain stem, but additional brain regions can be affected leading to cognitive impairment. Five to $10 \%$ of ALS cases have genetic causes, and disease-causing mutations have been identified in at least 25 loci (Zufiria et al., 2016).

These include mutations in the gene coding for the MAM-resident protein Sigma-1R, a chaperone regulating lipid and $\mathrm{Ca}^{2+}$ exchanges at the ER-mitochondria interface. Sigma-1R KO mice displayed axonal degeneration and motor neuron loss, leading to muscle weakness and deficits in locomotion (Bernard-Marissal et al., 2015). In vitro down-regulation or pharmacological inhibition of Sigma-1R resulted in motor neuron degeneration, associated with ER-mitochondria uncoupling, $\mathrm{Ca}^{2+}$ imbalance, ER stress and altered mitochondrial dynamics and transport. No effect of Sigma-1R ablation was observed in cultures of sensory neurons, but Sigma-1R down-regulation was shown to trigger acute degeneration of mouse hippocampal neurons and astrocytes in vitro (Hedskog et al., 2013). Future work will have to define how mutations in ubiquitously expressed proteins, such as Sigma-1R, are deleterious for some neuronal types but not for others.

Mutations in gene coding for the MAM-resident protein VAPB also cause ALS. VAPB was shown to interact with its partner at the OM membrane PTPIP51 both in cell lines and mouse spinal cord (De Vos et al., 2012; Stoica et al., 2014). As previously mentioned, this complex constitutes an ERmitochondria tether promoting $\mathrm{Ca}^{2+}$ transfers between the organelles and regulating autophagy (De Vos et al., 2012; Gomez-Suaga et al., 2017). The disease-causing P56S substitution in VAPB showed increased localization to the MAM, leading to stronger interaction with PTPIP51 and higher mitochondrial $\mathrm{Ca}^{2+}$ uptake in cell lines and cortical neurons (De Vos et al., 2012).

Finally, missense and nonsense mutations in the genes coding for Tar DNA binding protein 43 (TDP43) and fused in sarcoma (FUS), involved in transcription, splicing and mRNA transport, trigger protein aggregation and cause ALS. Cytosolic inclusions of wild-type forms of these proteins are present in some patients with sporadic forms of the disease. Overexpression of wild-type or mutant TDP-43 or FUS, decreased ER-mitochondria proximity in cell lines compared to controls, and similar changes were observed in spinal cords of TDP-43 or FUS transgenic mice that developed ALS (Stoica 
et al., 2014; Stoica et al., 2016). This phenotype was attributed to disruption of VAPB-PTPIP51 interaction by TDP-43 or FUS overexpression, leading to reduced ER-mitochondria coupling, $\mathrm{Ca}^{2+}$ exchanges and ATP production. It was dependent on activation of glycogen synthase kinase $3 \beta$ (GSK$3 \beta)$, as pharmacological inhibition of the kinase suppressed the defect in TDP-43 or FUS overexpressing cells. Down-regulation of either TDP-43 or FUS had no effect on ER-mitochondria coupling, suggesting that, under physiological conditions, these proteins do not interfere with the functions of the ER-mitochondria interface.

Similarly to PD, different ALS-causing mutations were associated with either increased or decreased cross-talk between ER and mitochondria. Moreover, protein inclusions were shown to interfere indirectly with the functions of the interface, as previously shown for $A \beta$ peptides and ApoE4 in $A D$ models, and $\alpha$-synuclein in PD.

\section{ER-mitochondria contact sites in neuroinflammation}

Chronic neuroinflammation in neurodegenerative disorders share several common pathological characteristics : (i) levels of proinflammatory cytokines are elevated in the brain, cerebrospinal fluid and serum; (ii) and microglial cells, the resident macrophages mediating immune surveillance in the central nervous system, are chronically activated in the affected brain regions (Hirsch and Hunot, 2009; McGeer and McGeer, 2007; Mrak and Griffin, 2005). Neuropathological and neuroradiological studies indicate that neuroinflammatory responses begin prior to significant loss of neuronal populations, suggesting that cytokine-driven neuroinflammation and neurotoxicity modify disease progression in these disorders (Hirsch et al., 2012). Chronic neuroinflammation could be mediated by several small molecular motifs specific of pathogens (pathogen-associated molecular patterns, PAMPs), or endogenous biomolecules released during trauma injury or degenerative processes (danger-/damage-associated molecular patterns, DAMPs or alarmins). These molecules bind to specific pattern recognition receptors (PRRs) of the host, including RIG-I-like (RLRs), Toll-like (TLRs) and Nod-like receptors (NLRs), to activate signaling cascades that promote pathogen elimination and tissue repair (Brubaker et al., 2015).

Mitochondria and ER have both been shown to orchestrate microglial responses, by providing platforms for signaling pathways involved in innate immunity response, and to contribute to neuroinflammation in neurodegenerative disorders (Abou-Sleiman et al., 2006; Browne et al., 1997; Hotamisligil, 2010; Querfurth and LaFerla, 2010). In 2011, the group of Tschopp provided one of the first links between neuroinflammation and the ER-mitochondria interface: they showed that the inflammasome component Nod-like receptor protein 3 (NLRP3) localizes to the ER under resting conditions, whereas it redistributes to the MAM fraction together with its adaptor ASC (Apoptosisassociated speck-like protein containing a CARD) in response to inflammation (Zhou et al., 2011). The 
NLRP3 inflammasome is a molecular platform activated by danger signals, broadly implicated in a variety of inflammatory conditions (Gross et al., 2011) and emerging as a key pro-inflammatory pathway in neurodegenerative diseases (Codolo et al., 2013; Heneka et al., 2013; Malhotra et al., 2015; Yan et al., 2015). In response to a variety of DAMPs, such as $A \beta$ and aggregated $\alpha$-synuclein (Codolo et al., 2013; Gustot et al., 2015), NLRP3 and ASC assemble into a complex that recruits and activates caspase 1, leading to production and release of interleukins (IL-1 $\beta$, IL-18, (Schroder and Tschopp, 2010), Figure 2). NLRP3 is the best-characterized member of the human NLR family, and is the only NLR inflammasome reported to act at the ER-mitochondria interface. NLRP3 inflammasome could be activated by either mitochondrial DAMPs (mtDNA, mtTFA, N-formyl peptides, CL (Shimada et al., 2012)) or reactive oxygen species (ROS) and ER stress (Menu et al., 2012; Murakami et al., 2012). A recent study demonstrated an induction of Thioredoxin interacting protein (TXNIP) through IRE1 $\alpha$ and PERK pathways in ER stress-induced NLRP3 activation (Oslowski et al., 2012). TXNIP is a critical node in UPR-dependent programmed cell death (Lerner et al., 2012). TXNIP is also activated by mitochondrial ROS, which promote TXNIP translocation to the MAM and its association with NLRP3 ((Lane et al., 2013; Zhou et al., 2010), Figure 2). Deletion of the TXNIP gene prevents NLRP3 inflammasome activation and subsequent IL-1 $\beta$ production in immune cells (Zhou et al., 2010).

Mitochondrial $\mathrm{Ca}^{2+}$ uptake from the ER plays a central role in NLRP3 inflammasome activation (Lee et al., 2012; Murakami et al., 2012; Rossol et al., 2012) and may involve VDACs as key players (Zhou et al., 2011). Zhou et al. showed that silencing VDAC isoforms 1 and 2 prevented inflammasome formation, IL-1 $1 \beta$ release and generation of mitochondrial ROS in response to NLRP3 agonists. Conversely, NLRP3 knockout macrophages exhibit higher VDAC protein levels than WT cells. VDAC1/2 may also mitigate NLRP3 inflammasome-dependent responses by serving as an anchoring platform at the ER-mitochondria interface for the anti-apoptotic Bcl-2 protein, which in turn will limit VDACdependent mitochondrial $\mathrm{Ca}^{2+}$ entry and the associated ROS production (Shimada et al., 2012; Zhou et al., 2011). By an alternative pathway, the membrane attack complex (MAC) formed by the polymerization of terminal components of the complement cascade, triggers NLRP3 inflammasome activation and IL- $1 \beta$ release, by a mechanism involving the $\mathrm{MCU}$ and $\mathrm{Ca}^{2+}$ accumulation in the mitochondrial matrix ((Triantafilou et al., 2013), Figure 2).

Mitochondrial dynamics has also been reported to regulate NLRP3 inflammasome activation. Infection by RNA viruses promotes the phosphorylation of Drp1, leading to mitochondrial fission and subsequent inflammasome activation (Park et al., 2015; Wang et al., 2014) . By yet another pathway, RNA viruses lead to inflammasome activation by a mechanism involving recruitment of NLRP3 by Mfn2 (Ichinohe et al., 2013). During RNA virus infection, RLRs are recruited to the MAM to bind the adaptor MAVS (mitochondrial anti-viral signaling) and form a signaling "synapse" that activates the interferon $\beta$ response (Horner et al., 2011). Ichinohe et al. showed that Mfn2 enhances the 
association between NLRP3 and MAVS (Ichinohe et al., 2013). Others have shown that the MAVS protein complex is required for optimal NLRP3 recruitment and inflammasome activity (Franchi et al., 2014; Park et al., 2013; Subramanian et al., 2013). Other members of this antiviral complex are recruited to the ER-mitochondria interface to fine-tune MAVS-NLRP3 signaling, including stimulator of IFN genes (STING) ((Abdul-Sater et al., 2013; Abe and Barber, 2014), Figure 2). Altogether, these findings warrant further studies evaluating the role of ER-mitochondria dynamics in the regulation of MAVS-dependent signaling.

Interestingly, Parkin has been recently shown to interact with both the MAVS and NLRP3 pathways. Parkin promotes MAVS modification by unanchored linear polyubiquitin chains, leading to an antiviral signaling cascade associated with interferon $\beta$ production (Khan et al., 2016). On the other hand, Parkin-dependent mitophagy prevents excessive NLRP3 activation by an NF-KB dependent mechanism ((Zhong et al., 2016), Figure 2).

Altogether, these data strongly support the critical role of the ER-mitochondria interface in neuroinflammation, and in particular in inflammasome activation.

\section{Caveats and difficulties in assessing the structure and function of the ER-mitochondria} interface

Efforts to link genetic causes or external insults to alterations in ER-mitochondria communication and finally neurodegeneration are inevitably confronted to a series of conceptual and methodological difficulties. The conceptual difficulties are tightly associated with the versatile and multitasking nature of the ER-mitochondria interface: alteration of this subcellular compartment is expected to have pleiotropic effects on cell homeostasis and survival, and the question of which defect comes first is extremely difficult to tackle. Deregulation of cellular processes beyond ER-mitochondria contacts could cause alterations of the interface by indirect mechanisms. For example, cells suffering from ER stress or mitochondrial respiratory deficiency, which are both hallmarks of neurodegenerative disorders, may remodel ER-mitochondria contacts in an attempt to cope with these primary defects. ER and mitochondria each share contact sites with other organelles, and recent studies in yeast have provided evidence for cross-regulations between different types of contacts (Elbaz-Alon et al., 2015; Elbaz-Alon et al., 2014; Honscher et al., 2014; Lang et al., 2015), adding further complexity to the interpretation of potential changes at the level of the ERmitochondria interface. So far, it has not been possible to determine whether alterations in ERmitochondria communication in disease models constitute primary defects, side-effects or compensatory mechanisms in the process of neurodegeneration (Figure 3).

Moreover, controversial observations regarding the involvement of specific proteins in the cross-talk between ER and mitochondria further complicate the dissection of the pathogenic mechanisms. The 
use of different cellular models (cell lines versus primary cultures) is certainly in part responsible for such discrepancies. Direct effects related to the absence of the protein of interest can be evaluated by its acute depletion. Such effects may be different from those induced by its chronic ablation, which could be accompanied by compensatory mechanisms. Moreover, transient or constitutive knock-out of a specific gene does not necessarily mimic the effect of mutations found in patient cells, where the protein may be inactive but present. Though biases are difficult to exclude, the possibility that different cellular models recapitulate different stages in the cellular response to the loss or gain of function of a specific protein should be considered, when interpreting the results. Cell culture conditions are another source of bias when studying the properties of the ER-mitochondria interface, especially in cellular models of neurodegeneration that are often particularly vulnerable to stress conditions. In agreement with this possibility, a recent study demonstrated an impact of the cell density at the moment of plating on the degree of ER-mitochondria juxtaposition and on expression levels of the MCU (Naon et al., 2016).

An additional confounding aspect is related to the multitude of terms used to describe the ERmitochondria interface. "ER-mitochondria contacts" and "MAM" are often applied in an interchangeable manner. However, in reality, the first term corresponds to subcellular structures observed by fluorescence or electron microscopy, and the second represents a subcellular fraction, obtained from crude mitochondria after separation by ultracentrifugation, usually on a Percoll gradient (Wieckowski et al., 2009). ER-mitochondria contacts are easily visualized in yeast, by following the distribution of fluorescently tagged components of ERMES complexes (Kornmann et al. 2009). In mammals, the identity of the structural complexes remains discussed, and many studies rather focus on the isolation of the MAM fraction. This fraction is a well-characterized entity, enriched in specific proteins and enzymatic activities, which are used as read-outs for its integrity (phospholipid biosynthesis, cholesterol metabolism, y-secretase activity, (Area-Gomez, 2014; Leal et al., 2016). It displays lipid raft properties, allowing further purification of detergent-resistant subfractions (Area-Gomez et al. 2012; Guardia-Laguarta et al., 2014). However, there is concern when knowledge about MAM fractions is directly transposed to properties of ER-mitochondria contacts. MAM composition is extremely complex, as highlighted by recent proteomic studies reporting the presence of several hundreds of proteins (Horner et al., 2015; Liu et al., 2015; Poston et al., 2013; Sala-Vila et al., 2016). Most of the proteins are not exclusive components of MAMs, and the association of some of them (Lynes et al., 2012) is determined by posttranslational modifications. Finally, the relative abundance of MAM components may vary depending on the experimental conditions, as illustrated by inconsistencies across studies. For all these reasons, the sole presence of a protein in MAMs should not be regarded as a proof of its direct involvement in physical or functional coupling of the ER and mitochondria. 
The methods used for the structural characterization of the ER-mitochondria interface are also prone to introduce bias in the observations. Measuring the colocalization of ER and mitochondrial markers is not the optimal approach for the assessment of organelle proximity, because of the limited resolution of confocal light microscopy $(200 \mathrm{~nm})$. Alternative fluorescent-based methods, such as Fluorescence Resonance Energy Transfer (FRET, (Csordas et al., 2010)), Proximity Ligation Assay (PLA, (Bernard-Marissal et al., 2015; De Vos et al., 2012; Hedskog et al., 2013; Stoica et al., 2016)) or dimerization-dependent fluorescence/luminescence (Alford et al., 2012; Lim et al., 2015; Naon et al., 2016), bypass this limitation by detecting specific interactions between ER and OM membranelocalized proteins. Super-resolution imaging approaches allow the assessment of changes in individual ER-mitochondria contacts, and are, so far, the most adapted method to investigate this subcellular compartment. However, they are particularly demanding in term of material, cost and time, which explains why their application in the field has been limited (Brunstein et al., 2013; Shim et al., 2012). Electron microscopy analyses have more often be used. Although more reliable than classical confocal imaging approaches, such analyses should take into account morphological alterations of the ER and mitochondria which may contribute to changes to the ER-mitochondria interface, e.g. ER dilatation, mitochondrial fragmentation, changes in OM-IM intermembrane spacing or subcellular distribution. In this direction, Naon et al. recently proposed the use of an ERmitochondria contact coefficient that measures ER-mitochondria proximity on electron micrographs by combining three parameters: the width and length of the contact site, as well as the perimeter of mitochondria involved in the interaction (Naon et al., 2016).

Measurement of lipid or $\mathrm{Ca}^{2+}$ exchanges between ER and mitochondria could also be influenced by parameters independent of ER-mitochondria juxtaposition. For instance, perturbations in ER $\mathrm{Ca}^{2+}$ storing and releasing capacity or in mitochondrial $\mathrm{Ca}^{2+}$ uptake have an impact on ER-to-mitochondria $\mathrm{Ca}^{2+}$ transfers, and could therefore bias the effect related to altered interorganellar proximity. Several studies have taken into account some of these parameters (de Brito and Scorrano, 2008; Filadi et al., 2015; Gautier et al., 2016; Zampese et al., 2011), but control experiments should be routinely used when assessing the functional integrity of the ER-mitochondria interface.

In conclusion, combination of different cell/animal models and methodological approaches, as well as the establishment of general guidelines on how to assess the ER-mitochondria contact structure and function, should help reconciling contradictory observations concerning the role of specific proteins in the regulation of ER-mitochondria coupling and facilitate the study of this interface in neurodegeneration. 


\section{Conclusions-perspectives}

The ER-mitochondria interface has emerged as a central subcellular compartment regulating a number of vital cellular processes. It is thus not surprising that a body of recent literature links defects in ER-mitochondria communication to pathological features associated with neurodegenerative diseases, such as protein inclusions, ER stress, mitochondrial dysfunction and neuroinflammation. The most compelling evidence for such defects has been provided in familial forms of these diseases, warranting further investigations to determine in how far they are more generally relevant to the sporadic forms. Moreover, most of the perturbations reported so far have been described in non-neuronal models, and their impact on neuronal homeostasis and survival remains to be proven. The disease-causing mutations associated with defects in ER-mitochondria communication most often affect the function of ubiquitously expressed proteins, and the molecular mechanisms underlying the selective vulnerability of the neuronal populations affected in each specific disease remain obscure. This raises the question of how specificities in ER-mitochondria structure and function might contribute to shape cell-specific effects. As a corollary, future work will have to address the possibility that defects in ER-mitochondria communication in immune and glial cells contribute to neurodegeneration. Moving forward towards these central issues will have to be paralleled by methodological and technical improvements for the reliable analysis of this fascinating subcellular compartment.

\section{Acknowledgements}

We apologize to all colleagues whose work has been incompletely or not cited in this review due to space limitations. This work was supported by Institut national de la santé et de la recherche médicale, Fondation de France (grant Engt 2012 00034508), AETIONOMY (Innovative Medicines Initiative Joint Undertaking under grant agreement $n^{\circ} 115568$, EFPIA companies' in kind contribution), Fondation Institut du Cerveau et de la Moelle épinière, and Agence Nationale pour la Recherche ("Investissements d'avenir", grant ANR-10-IAIHU-06). 


\begin{tabular}{|c|c|c|c|}
\hline $\begin{array}{l}\text { Neurodegenerative disorder } \\
\quad \text { and associated } \\
\text { neuropathological hallmarks }\end{array}$ & Involved protein & Association with MAM fraction & Defects in ER-mitochondria coupling, model \\
\hline $\begin{array}{l}\text { Alzheimer's disease }(A D) \\
\text { - loss of hippocampal and cortical } \\
\text { neurons } \\
\text { - intracellular inclusions of } \\
\text { hyperphorsphorylated tau } \\
\text { - extracellular deposits of } A \beta \\
\text { peptides }\end{array}$ & $\begin{array}{l}\text { Presenilin } 1 \text { (PS1) } \\
\text { Presenilin } 2 \text { (PS2) } \\
\text { Amyloid precursor protein (APP) } \\
\text { Apolipoprotein E isotype } 4 \text { (ApoE4) }\end{array}$ & $\begin{array}{l}\text { mouse brain (Area-Gomez et al., } \\
\text { 2009); } \uparrow \text { for AD-associated variant } \\
\text { N141I (Filadi et al., 2016) } \\
\text { mouse brain (Area-Gomez et al., } \\
\text { 2009); A } \beta \text { produced at the MAM } \\
\text { (Schreiner et al., 2015) } \\
\text { not tested }\end{array}$ & 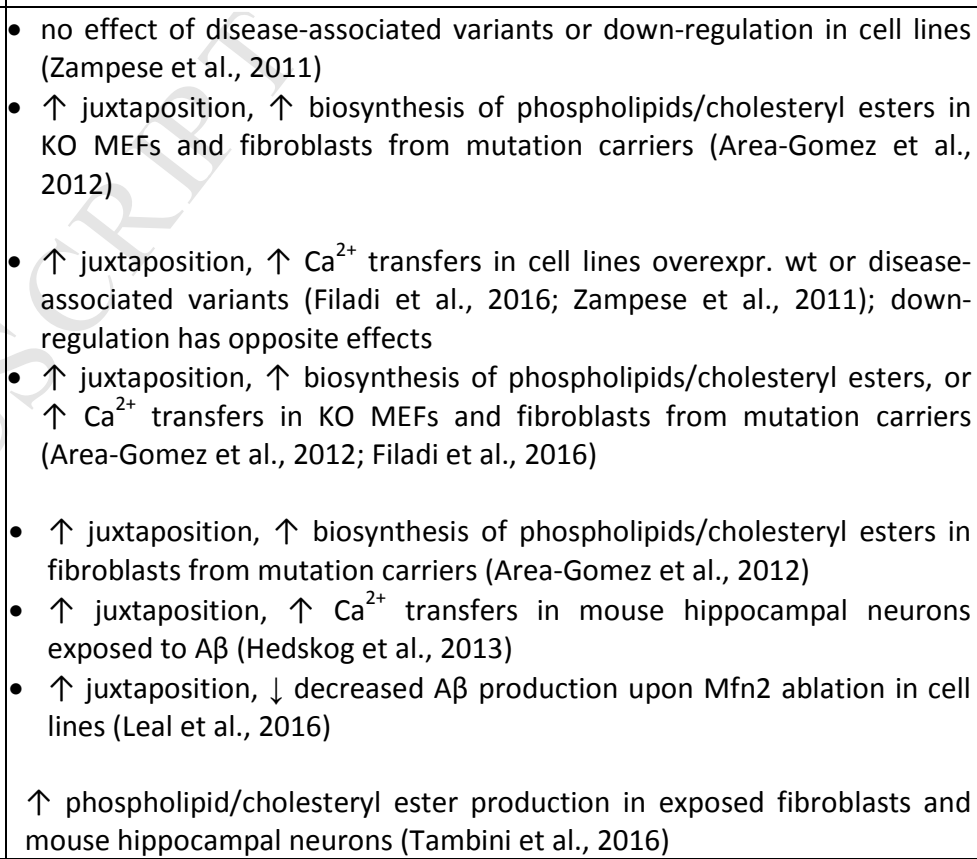 \\
\hline $\begin{array}{l}\text { Parkinson's disease (PD) } \\
\text { - loss of dopaminergic neurons of } \\
\text { the substantia nigra pars } \\
\text { compacta } \\
\text { - intracellular inclusions of } \alpha \text { - } \\
\text { synuclein }\end{array}$ & $\begin{array}{l}\text { Protein deglycase DJ-1 } \\
\text { Parkin }\end{array}$ & $\begin{array}{l}\text { cell lines, mouse and human brain } \\
\text { (Guardia-Laguarta et al., 2014); } \downarrow \\
\text { for disease-associated variants } \\
\text { A30P and A53T } \\
\text { mouse brain } \\
\text { rat cortical neurons, upon exposure } \\
\text { to glutamate (Van Laar et al., } \\
\text { 2015); cell lines (Gelmetti et al., } \\
\text { 2017) }\end{array}$ & 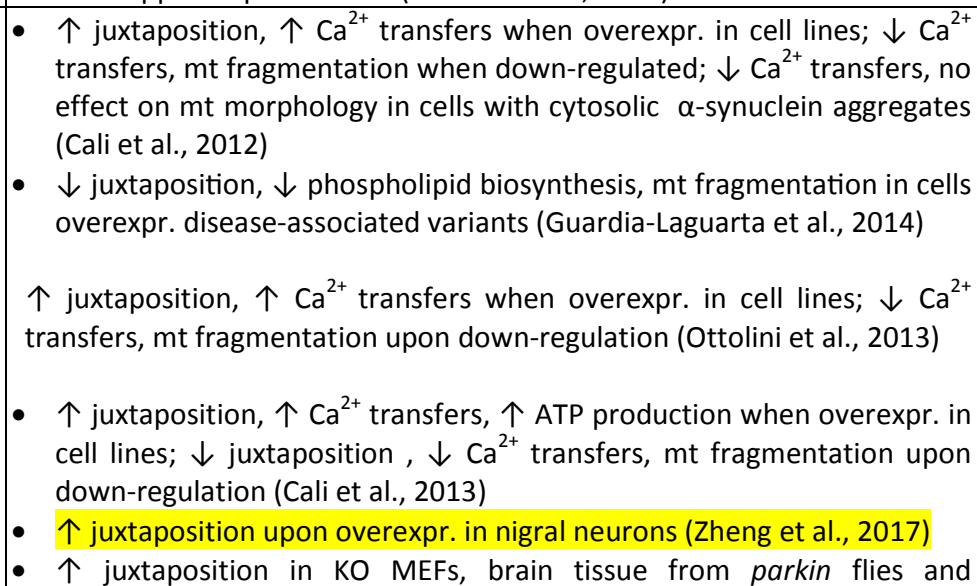 \\
\hline
\end{tabular}




\begin{tabular}{|c|c|c|c|}
\hline & $\begin{array}{l}\text { PTEN induced putative kinase } 1 \\
\text { (PINK1) }\end{array}$ & $\begin{array}{l}\text { cell lines ((Gelmetti et al., 2017); } \\
\text { our unpublished data) }\end{array}$ & $\begin{array}{l}\text { fibroblasts from mutation carriers; } \uparrow \text { ER-to-mitochondria } \mathrm{Ca}^{2+} \text { transfers } \\
\text { in KO MEFs and fibroblasts/iPSC-derived neurons from mutation } \\
\text { carriers (Celardo et al., 2016; Gautier et al., 2016) } \\
\text { - } \text { juxtaposition in brain tissue from pink1 flies and fibroblasts from } \\
\text { mutation carriers (Celardo et al., 2016) } \\
\text { - } \uparrow \text { juxtaposition due to presence in the MAM upon induction of } \\
\text { mitophagy in cell lines (Gelmetti et al., 2017) }\end{array}$ \\
\hline $\begin{array}{l}\text { Amyotrophic lateral sclerosis (ALS) } \\
\text { - loss of motor neurons } \\
\text { - inclusions of SOD1, TDP-43, FUS } \\
\text { or p62 }\end{array}$ & $\begin{array}{l}\text { Sigma-1 receptor } \\
\text { Vesicle-associated membrane } \\
\text { protein-associated protein B } \\
\text { (VAPB) } \\
\text { Tar DNA binding protein } 43 \text { (TDP- } \\
\text { 43) } \\
\text { Fused in sarcoma (FUS) }\end{array}$ & $\begin{array}{l}\text { cell lines (Hayashi and Su, 2007) } \\
\text { in cell lines, together with OM } \\
\text { membrane protein PTPIP51; } \uparrow \text { for } \\
\text { disease-associated variant } \\
\text { VAPBP56S } \\
\text { not present } \\
\text { not present }\end{array}$ & $\begin{array}{l}\downarrow \text { juxtaposition, perturbed } \mathrm{Ca}^{2+} \text { signaling, cell death when down- } \\
\text { regulated in mouse motor neurons (Bernard-Marissal et al., 2015) } \\
\text { - } \quad \downarrow \text { juxtaposition, } \downarrow \mathrm{Ca}^{2+} \text { transfers, } \uparrow \text { autophagy upon down-regulation } \\
\text { of VAPB or PTPIP51 in cell lines } \\
\text { - } \text { VAPBP56S expr. leads to } \uparrow \text { interaction with PTPIP51, } \uparrow \mathrm{mt} \mathrm{Ca}^{2+} \text { uptake, } \\
\text { mt clustering in cell lines (De Vos et al., 2012; Gomez-Suaga et al., 2017) } \\
\text { - } \text { No effect of down-regulation } \\
\text { - } \downarrow \text { juxtaposition, } \downarrow \mathrm{Ca}^{2+} \text { transfers, disruption of VAPB-PTPIP51 } \\
\text { interaction, when overexpr. wt or disease-related substitutions } \\
\text { (M337V, Q331K, A382T, G384C) in cell lines and in motor neurons of } \\
\text { mouse model (Stoica et al., 2014) } \\
\text { - No effect of down-regulation } \\
\text { - } \downarrow \text { juxtaposition, } \downarrow \mathrm{Ca}^{2+} \text { transfers, } \downarrow \text { ATP production when overexpr. } \\
\text { wt or disease-related substitutions (R521C, R518K) in cell lines and in } \\
\text { motor neurons of mouse model (Stoica et al., 2016) }\end{array}$ \\
\hline $\begin{array}{l}\text { Hereditary Spastic Paraplegia (HSP) } \\
\text { axonopathy of corticospinal motor } \\
\text { neurons }\end{array}$ & $\begin{array}{l}\text { Receptor expression enhancing } \\
\text { protein } 1 \text { (Reep1) }\end{array}$ & mouse brain & $\begin{array}{l}\text { Expression of wt, but not of disease-related mutant forms, increases ER- } \\
\text { mitochondria proximity in cell lines (Lim et al., 2015) }\end{array}$ \\
\hline $\begin{array}{l}\text { Charcot Marie Tooth (CMT) } \\
\text { Demyelination (type II) or } \\
\text { axonopathy (type I, III and IV) of } \\
\text { the peripheral nerve }\end{array}$ & $\begin{array}{l}\text { Mitofusin } 2 \text { (Mfn2) } \\
\text { Ganglioside-induced differentiation } \\
\text { associated protein } 1 \text { (GDAP1) } \\
\text { Diacylglycerol O-acyltransferase } 2\end{array}$ & $\begin{array}{l}\text { mouse brain } \\
\text { cell lines (Stone et al., 2009) }\end{array}$ & 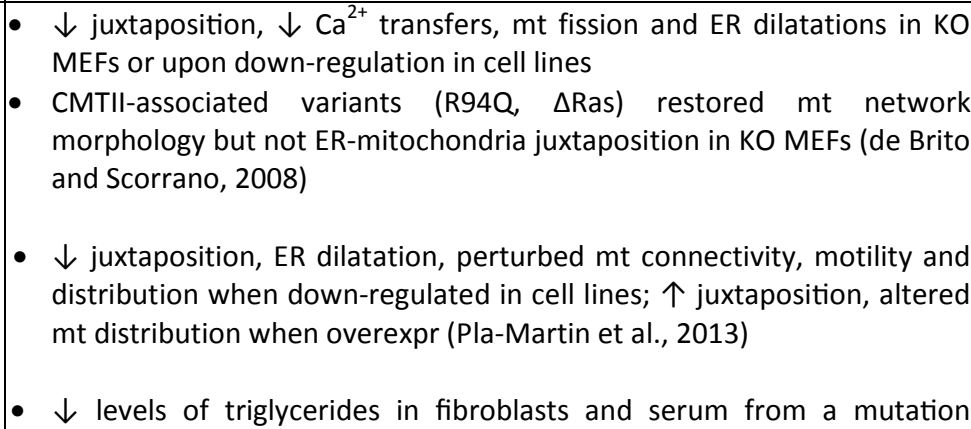 \\
\hline
\end{tabular}




\begin{tabular}{|l|l|l|}
\hline & (DGAT2) & $\begin{array}{l}\text { carrier } \\
\text { expression of CMT-associated variant Y223H impairs axon branching in } \\
\text { zebrafish motor neurons (Hong et al., 2016) }\end{array}$ \\
\hline
\end{tabular}

Table 1. Overview of currently available information on the involvement of neurodegenerative disease-related proteins in ER-mitochondria coupling (mt, mitochondrial; wt, wild-type). 


\section{Figure Legends}

Figure 1. Cross-talk between cellular metabolism, membrane dynamics and signaling at ERmitochondria contacts. Contact sites between ER and mitochondria are crucial for phospholipid biosynthesis, mediated by ER (PS synthase and PE N-methyltransferase-2) and IM membranelocalized (PS decarboxylase) enzymes. They are also required for mitochondrial $\mathrm{Ca}^{2+}$ uptake, as they facilitate the coupling of $\mathrm{IP}_{3} \mathrm{R}$-mediated $\mathrm{Ca}^{2+}$ release from the ER to $\mathrm{Ca}^{2+}$ import into the matrix by VDACs and the MCU. $\mathrm{Ca}^{2+}$ in the mitochondrial matrix regulates the activity of several enzymes of the Krebs cycle and the ATP synthase, thus promoting ATP production. Mitochondrial $\mathrm{Ca}^{2+}$ overload, on the other hand, triggers MPTP opening, leading to caspase activation and apoptosis. ER-mitochondria contact sites are also involved in the constriction of mitochondria and Drp1 recruitment prior to mitochondrial fission, as well as in autophagosome formation. Cross-regulation between the different functions of the ER-mitochondria interface (illustrated by the arrows) is crucial to cellular homeostasis and adaptation to stress.

Figure 2. Regulation of NLRP3 inflammasome activation at the ER-mitochondria interface. NLRP3, ASC and pro-caspase 1 assemble into a complex called the NLRP3 inflammasome, which leads to maturation of IL-1 $\beta$ and IL-18. The NLRP3 inflammasome can be activated by mitochondrial danger signals (mtDNA, mtTFA, cardiolipin, ROS) and ER stress, through its interaction with TXNIP. Mitochondrial ROS promote TXNIP translocation to the ER-mitochondria interface and its association with NLRP3. Mitochondrial $\mathrm{Ca}^{2+}$ uptake from the ER, regulated by VDACs of the OM and the MCU of the IM membrane, is also involved in NLRP3 inflammasome activation. MAVS and its partner STING are required for NLRP3 recruitment and inflammasome activity. Parkin-dependent mitophagy has been reported to mitigate excessive NLRP3 activation.

Figure 3. Complex crosstalk between pathogenic pathways triggered by disease-causing mutations and ER-mitochondria coupling in neurodegeneration. Disease-causing mutations may directly affect ER-mitochondria communication, leading to pleiotropic side effects on ER folding capacity, $\mathrm{Ca}^{2+}$ homeostasis, mitochondria dynamics and metabolism, autophagy and apoptosis. Alternatively, the disease-causing mutations may impair ER and/or mitochondrial functions, or trigger protein aggregation, which could in turn impinge on the structural and functional features of the ERmitochondria interface. Remodeling of ER-mitochondria contacts may also occur as a compensatory mechanism in response to a primary defect situated elsewhere. All these mechanisms are not mutually exclusive and may participate at some stage to the disease process. In the long term, chronic deregulation of ER-mitochondria coupling is expected to accelerate neurodegeneration. 


\section{References}

Abdul-Sater, A.A., Tattoli, I., Jin, L., Grajkowski, A., Levi, A., Koller, B.H., Allen, I.C., Beaucage, S.L., Fitzgerald, K.A., Ting, J.P., Cambier, J.C., Girardin, S.E., Schindler, C., 2013. Cyclic-di-GMP and cyclic-diAMP activate the NLRP3 inflammasome. EMBO Rep 14, 900-906.

Abe, T., Barber, G.N., 2014. Cytosolic-DNA-mediated, STING-dependent proinflammatory gene induction necessitates canonical NF-kappaB activation through TBK1. J Virol 88, 5328-5341.

Abou-Sleiman, P.M., Muqit, M.M., Wood, N.W., 2006. Expanding insights of mitochondrial dysfunction in Parkinson's disease. Nat Rev Neurosci 7, 207-219.

Alford, S.C., Ding, Y., Simmen, T., Campbell, R.E., 2012. Dimerization-dependent green and yellow fluorescent proteins. ACS Synth Biol 1, 569-575.

Arasaki, K., Shimizu, H., Mogari, H., Nishida, N., Hirota, N., Furuno, A., Kudo, Y., Baba, M., Baba, N., Cheng, J., Fujimoto, T., Ishihara, N., Ortiz-Sandoval, C., Barlow, L.D., Raturi, A., Dohmae, N., Wakana, Y., Inoue, H., Tani, K., Dacks, J.B., Simmen, T., Tagaya, M., 2015. A role for the ancient SNARE syntaxin 17 in regulating mitochondrial division. Dev Cell 32, 304-317.

Area-Gomez, E., 2014. Assessing the function of mitochondria-associated ER membranes. Methods Enzymol 547, 181-197.

Area-Gomez, E., de Groof, A.J., Boldogh, I., Bird, T.D., Gibson, G.E., Koehler, C.M., Yu, W.H., Duff, K.E., Yaffe, M.P., Pon, L.A., Schon, E.A., 2009. Presenilins are enriched in endoplasmic reticulum membranes associated with mitochondria. Am J Pathol 175, 1810-1816.

Area-Gomez, E., Del Carmen Lara Castillo, M., Tambini, M.D., Guardia-Laguarta, C., de Groof, A.J., Madra, M., Ikenouchi, J., Umeda, M., Bird, T.D., Sturley, S.L., Schon, E.A., 2012. Upregulated function of mitochondria-associated ER membranes in Alzheimer disease. EMBO J 31, 4106-4123.

Arruda, A.P., Pers, B.M., Parlakgul, G., Guney, E., Inouye, K., Hotamisligil, G.S., 2014. Chronic enrichment of hepatic endoplasmic reticulum-mitochondria contact leads to mitochondrial dysfunction in obesity. Nat Med 20, 1427-1435.

Baughman, J.M., Perocchi, F., Girgis, H.S., Plovanich, M., Belcher-Timme, C.A., Sancak, Y., Bao, X.R., Strittmatter, L., Goldberger, O., Bogorad, R.L., Koteliansky, V., Mootha, V.K., 2011. Integrative genomics identifies $\mathrm{MCU}$ as an essential component of the mitochondrial calcium uniporter. Nature 476, 341-345.

Belgareh-Touze, N., Cavellini, L., Cohen, M.M., 2016. Ubiquitination of ERMES components by the E3 ligase Rsp5 is involved in mitophagy. Autophagy, 1-19.

Bernard-Marissal, N., Medard, J.J., Azzedine, H., Chrast, R., 2015. Dysfunction in endoplasmic reticulum-mitochondria crosstalk underlies SIGMAR1 loss of function mediated motor neuron degeneration. Brain 138, 875-890.

Betz, C., Stracka, D., Prescianotto-Baschong, C., Frieden, M., Demaurex, N., Hall, M.N., 2013. Feature Article: mTOR complex 2-Akt signaling at mitochondria-associated endoplasmic reticulum membranes (MAM) regulates mitochondrial physiology. Proc Natl Acad Sci U S A 110, 12526-12534.

Bockler, S., Westermann, B., 2014. Mitochondrial ER contacts are crucial for mitophagy in yeast. Dev Cell 28, 450-458.

Bravo, R., Vicencio, J.M., Parra, V., Troncoso, R., Munoz, J.P., Bui, M., Quiroga, C., Rodriguez, A.E., Verdejo, H.E., Ferreira, J., Iglewski, M., Chiong, M., Simmen, T., Zorzano, A., Hill, J.A., Rothermel, B.A., Szabadkai, G., Lavandero, S., 2011. Increased ER-mitochondrial coupling promotes mitochondrial respiration and bioenergetics during early phases of ER stress. J Cell Sci 124, 2143-2152.

Browne, S.E., Bowling, A.C., MacGarvey, U., Baik, M.J., Berger, S.C., Muqit, M.M., Bird, E.D., Beal, M.F., 1997. Oxidative damage and metabolic dysfunction in Huntington's disease: selective vulnerability of the basal ganglia. Ann Neurol 41, 646-653.

Brubaker, S.W., Bonham, K.S., Zanoni, I., Kagan, J.C., 2015. Innate immune pattern recognition: a cell biological perspective. Annu Rev Immunol 33, 257-290.

Brunstein, M., Wicker, K., Herault, K., Heintzmann, R., Oheim, M., 2013. Full-field dual-color 100-nm super-resolution imaging reveals organization and dynamics of mitochondrial and ER networks. Opt Express 21, 26162-26173. 
Bui, M., Gilady, S.Y., Fitzsimmons, R.E., Benson, M.D., Lynes, E.M., Gesson, K., Alto, N.M., Strack, S., Scott, J.D., Simmen, T., 2010. Rab32 modulates apoptosis onset and mitochondria-associated membrane (MAM) properties. J Biol Chem 285, 31590-31602.

Cali, T., Ottolini, D., Negro, A., Brini, M., 2012. alpha-Synuclein controls mitochondrial calcium homeostasis by enhancing endoplasmic reticulum-mitochondria interactions. J Biol Chem 287, 17914-17929.

Cali, T., Ottolini, D., Negro, A., Brini, M., 2013. Enhanced parkin levels favor ER-mitochondria crosstalk and guarantee $\mathrm{Ca}(2+)$ transfer to sustain cell bioenergetics. Biochim Biophys Acta 1832, 495-508.

Cardenas, C., Miller, R.A., Smith, I., Bui, T., Molgo, J., Muller, M., Vais, H., Cheung, K.H., Yang, J., Parker, I., Thompson, C.B., Birnbaum, M.J., Hallows, K.R., Foskett, J.K., 2010. Essential regulation of cell bioenergetics by constitutive InsP3 receptor Ca2+ transfer to mitochondria. Cell 142, 270-283.

Celardo, I., Costa, A.C., Lehmann, S., Jones, C., Wood, N., Mencacci, N.E., Mallucci, G.R., Loh, S.H., Martins, L.M., 2016. Mitofusin-mediated ER stress triggers neurodegeneration in pink1/parkin models of Parkinson's disease. Cell Death Dis 7, e2271.

Chen, R., Valencia, I., Zhong, F., McColl, K.S., Roderick, H.L., Bootman, M.D., Berridge, M.J., Conway, S.J., Holmes, A.B., Mignery, G.A., Velez, P., Distelhorst, C.W., 2004. Bcl-2 functionally interacts with inositol 1,4,5-trisphosphate receptors to regulate calcium release from the ER in response to inositol 1,4,5-trisphosphate. J Cell Biol 166, 193-203.

Codolo, G., Plotegher, N., Pozzobon, T., Brucale, M., Tessari, I., Bubacco, L., de Bernard, M., 2013. Triggering of inflammasome by aggregated alpha-synuclein, an inflammatory response in synucleinopathies. PLoS One 8, e55375.

Copeland, D.E., Dalton, A.J., 1959. An association between mitochondria and the endoplasmic reticulum in cells of the pseudobranch gland of a teleost. J Biophys Biochem Cytol 5, 393-396.

Corti, O., Brice, A., 2013. Mitochondrial quality control turns out to be the principal suspect in parkin and PINK1-related autosomal recessive Parkinson's disease. Curr Opin Neurobiol 23, 100-108.

Cosson, P., Marchetti, A., Ravazzola, M., Orci, L., 2012. Mitofusin-2 independent juxtaposition of endoplasmic reticulum and mitochondria: an ultrastructural study. PLoS One 7, e46293.

Csordas, G., Renken, C., Varnai, P., Walter, L., Weaver, D., Buttle, K.F., Balla, T., Mannella, C.A., Hajnoczky, G., 2006. Structural and functional features and significance of the physical linkage between ER and mitochondria. J Cell Biol 174, 915-921.

Csordas, G., Varnai, P., Golenar, T., Roy, S., Purkins, G., Schneider, T.G., Balla, T., Hajnoczky, G., 2010. Imaging interorganelle contacts and local calcium dynamics at the ER-mitochondrial interface. Mol Cell 39, 121-132.

de Brito, O.M., Scorrano, L., 2008. Mitofusin 2 tethers endoplasmic reticulum to mitochondria. Nature 456, 605-610.

De Stefani, D., Raffaello, A., Teardo, E., Szabo, I., Rizzuto, R., 2011. A forty-kilodalton protein of the inner membrane is the mitochondrial calcium uniporter. Nature 476, 336-340.

De Vos, K.J., Morotz, G.M., Stoica, R., Tudor, E.L., Lau, K.F., Ackerley, S., Warley, A., Shaw, C.E., Miller, C.C., 2012. VAPB interacts with the mitochondrial protein PTPIP51 to regulate calcium homeostasis. Hum Mol Genet 21, 1299-1311.

Elbaz-Alon, Y., Eisenberg-Bord, M., Shinder, V., Stiller, S.B., Shimoni, E., Wiedemann, N., Geiger, T., Schuldiner, M., 2015. Lam6 Regulates the Extent of Contacts between Organelles. Cell Rep 12, 7-14.

Elbaz-Alon, Y., Rosenfeld-Gur, E., Shinder, V., Futerman, A.H., Geiger, T., Schuldiner, M., 2014. A dynamic interface between vacuoles and mitochondria in yeast. Dev Cell 30, 95-102.

Elgass, K.D., Smith, E.A., LeGros, M.A., Larabell, C.A., Ryan, M.T., 2015. Analysis of ER-mitochondria contacts using correlative fluorescence microscopy and soft X-ray tomography of mammalian cells. J Cell Sci 128, 2795-2804.

Filadi, R., Greotti, E., Turacchio, G., Luini, A., Pozzan, T., Pizzo, P., 2015. Mitofusin 2 ablation increases endoplasmic reticulum-mitochondria coupling. Proc Natl Acad Sci U S A 112, E2174-2181. 
Filadi, R., Greotti, E., Turacchio, G., Luini, A., Pozzan, T., Pizzo, P., 2016. Presenilin 2 Modulates Endoplasmic Reticulum-Mitochondria Coupling by Tuning the Antagonistic Effect of Mitofusin 2. Cell Rep 15, 2226-2238.

Franchi, L., Eigenbrod, T., Munoz-Planillo, R., Ozkurede, U., Kim, Y.G., Chakrabarti, A., Gale, M., Jr., Silverman, R.H., Colonna, M., Akira, S., Nunez, G., 2014. Cytosolic double-stranded RNA activates the NLRP3 inflammasome via MAVS-induced membrane permeabilization and K+ efflux. J Immunol 193, 4214-4222.

Friedman, J.R., Lackner, L.L., West, M., DiBenedetto, J.R., Nunnari, J., Voeltz, G.K., 2011. ER tubules mark sites of mitochondrial division. Science 334, 358-362.

Garcia-Perez, C., Hajnoczky, G., Csordas, G., 2008. Physical coupling supports the local Ca2+ transfer between sarcoplasmic reticulum subdomains and the mitochondria in heart muscle. J Biol Chem 283, 32771-32780.

Gautier, C.A., Erpapazoglou, Z., Mouton-Liger, F., Muriel, M.P., Cormier, F., Bigou, S., Duffaure, S., Girard, M., Foret, B., Iannielli, A., Broccoli, V., Dalle, C., Bohl, D., Michel, P.P., Corvol, J.C., Brice, A., Corti, O., 2016. The endoplasmic reticulum-mitochondria interface is perturbed in PARK2 knockout mice and patients with PARK2 mutations. Hum Mol Genet 25, 2972-2984.

Gelmetti, V., De Rosa, P., Torosantucci, L., Marini, E.S., Romagnoli, A., Di Rienzo, M., Arena, G., Vignone, D., Fimia, G.M., Valente, E.M., 2017. PINK1 and BECN1 relocalize at mitochondriaassociated membranes during mitophagy and promote ER-mitochondria tethering and autophagosome formation. Autophagy, 1-16.

Giacomello, M., Pellegrini, L., 2016. The coming of age of the mitochondria-ER contact: a matter of thickness. Cell Death Differ 23, 1417-1427.

Giorgi, C., Ito, K., Lin, H.K., Santangelo, C., Wieckowski, M.R., Lebiedzinska, M., Bononi, A., Bonora, M., Duszynski, J., Bernardi, R., Rizzuto, R., Tacchetti, C., Pinton, P., Pandolfi, P.P., 2010. PML regulates apoptosis at endoplasmic reticulum by modulating calcium release. Science 330, 1247-1251.

Gomez-Suaga, P., Paillusson, S., Stoica, R., Noble, W., Hanger, D.P., Miller, C.C., 2017. The ERMitochondria Tethering Complex VAPB-PTPIP51 Regulates Autophagy. Curr Biol 27, 371-385.

Gross, O., Thomas, C.J., Guarda, G., Tschopp, J., 2011. The inflammasome: an integrated view. Immunol Rev 243, 136-151.

Guardia-Laguarta, C., Area-Gomez, E., Rub, C., Liu, Y., Magrane, J., Becker, D., Voos, W., Schon, E.A., Przedborski, S., 2014. alpha-Synuclein is localized to mitochondria-associated ER membranes. J Neurosci 34, 249-259.

Gustot, A., Gallea, J.I., Sarroukh, R., Celej, M.S., Ruysschaert, J.M., Raussens, V., 2015. Amyloid fibrils are the molecular trigger of inflammation in Parkinson's disease. Biochem J 471, 323-333.

Hailey, D.W., Rambold, A.S., Satpute-Krishnan, P., Mitra, K., Sougrat, R., Kim, P.K., LippincottSchwartz, J., 2010. Mitochondria supply membranes for autophagosome biogenesis during starvation. Cell 141, 656-667.

Hamasaki, M., Furuta, N., Matsuda, A., Nezu, A., Yamamoto, A., Fujita, N., Oomori, H., Noda, T., Haraguchi, T., Hiraoka, Y., Amano, A., Yoshimori, T., 2013. Autophagosomes form at ER-mitochondria contact sites. Nature 495, 389-393.

Hayashi, T., Su, T.P., 2007. Sigma-1 receptor chaperones at the ER-mitochondrion interface regulate $\mathrm{Ca}(2+)$ signaling and cell survival. Cell 131, 596-610.

Hedskog, L., Pinho, C.M., Filadi, R., Ronnback, A., Hertwig, L., Wiehager, B., Larssen, P., Gellhaar, S., Sandebring, A., Westerlund, M., Graff, C., Winblad, B., Galter, D., Behbahani, H., Pizzo, P., Glaser, E., Ankarcrona, M., 2013. Modulation of the endoplasmic reticulum-mitochondria interface in Alzheimer's disease and related models. Proc Natl Acad Sci U S A 110, 7916-7921.

Heneka, M.T., Kummer, M.P., Stutz, A., Delekate, A., Schwartz, S., Vieira-Saecker, A., Griep, A., Axt, D., Remus, A., Tzeng, T.C., Gelpi, E., Halle, A., Korte, M., Latz, E., Golenbock, D.T., 2013. NLRP3 is activated in Alzheimer's disease and contributes to pathology in APP/PS1 mice. Nature 493, 674-678. Hernandez, D.G., Reed, X., Singleton, A.B., 2016. Genetics in Parkinson disease: Mendelian versus non-Mendelian inheritance. J Neurochem 139 Suppl 1, 59-74. 
Hirsch, E.C., Hunot, S., 2009. Neuroinflammation in Parkinson's disease: a target for neuroprotection? Lancet Neurol 8, 382-397.

Hirsch, E.C., Vyas, S., Hunot, S., 2012. Neuroinflammation in Parkinson's disease. Parkinsonism Relat Disord 18 Suppl 1, S210-212.

Hong, Y.B., Kang, J., Kim, J.H., Lee, J., Kwak, G., Hyun, Y.S., Nam, S.H., Hong, H.D., Choi, Y.R., Jung, S.C., Koo, H., Lee, J.E., Choi, B.O., Chung, K.W., 2016. DGAT2 Mutation in a Family with AutosomalDominant Early-Onset Axonal Charcot-Marie-Tooth Disease. Hum Mutat 37, 473-480.

Honscher, C., Mari, M., Auffarth, K., Bohnert, M., Griffith, J., Geerts, W., van der Laan, M., Cabrera, M., Reggiori, F., Ungermann, C., 2014. Cellular metabolism regulates contact sites between vacuoles and mitochondria. Dev Cell 30, 86-94.

Hoppins, S., Collins, S.R., Cassidy-Stone, A., Hummel, E., Devay, R.M., Lackner, L.L., Westermann, B., Schuldiner, M., Weissman, J.S., Nunnari, J., 2011. A mitochondrial-focused genetic interaction map reveals a scaffold-like complex required for inner membrane organization in mitochondria. J Cell Biol 195, 323-340.

Horner, S.M., Liu, H.M., Park, H.S., Briley, J., Gale, M., Jr., 2011. Mitochondrial-associated endoplasmic reticulum membranes (MAM) form innate immune synapses and are targeted by hepatitis C virus. Proc Natl Acad Sci U S A 108, 14590-14595.

Horner, S.M., Wilkins, C., Badil, S., Iskarpatyoti, J., Gale, M., Jr., 2015. Proteomic analysis of mitochondrial-associated ER membranes (MAM) during RNA virus infection reveals dynamic changes in protein and organelle trafficking. PLoS One 10, e0117963.

Hotamisligil, G.S., 2010. Endoplasmic reticulum stress and the inflammatory basis of metabolic disease. Cell 140, 900-917.

Huang, G., Vercesi, A.E., Docampo, R., 2013. Essential regulation of cell bioenergetics in Trypanosoma brucei by the mitochondrial calcium uniporter. Nat Commun 4, 2865.

Ichinohe, T., Yamazaki, T., Koshiba, T., Yanagi, Y., 2013. Mitochondrial protein mitofusin 2 is required for NLRP3 inflammasome activation after RNA virus infection. Proc Natl Acad Sci U S A 110, 1796317968.

Iwasawa, R., Mahul-Mellier, A.L., Datler, C., Pazarentzos, E., Grimm, S., 2011. Fis1 and Bap31 bridge the mitochondria-ER interface to establish a platform for apoptosis induction. EMBO J 30, 556-568.

Jellinger, K.A., 2010. Basic mechanisms of neurodegeneration: a critical update. J Cell Mol Med 14, 457-487.

Khan, M., Syed, G.H., Kim, S.J., Siddiqui, A., 2016. Hepatitis B Virus-Induced Parkin-Dependent Recruitment of Linear Ubiquitin Assembly Complex (LUBAC) to Mitochondria and Attenuation of Innate Immunity. PLoS Pathog 12, e1005693.

Kornmann, B., Currie, E., Collins, S.R., Schuldiner, M., Nunnari, J., Weissman, J.S., Walter, P., 2009. An ER-mitochondria tethering complex revealed by a synthetic biology screen. Science 325, 477-481.

Krols, M., van Isterdael, G., Asselbergh, B., Kremer, A., Lippens, S., Timmerman, V., Janssens, S., 2016. Mitochondria-associated membranes as hubs for neurodegeneration. Acta Neuropathol 131, 505523.

Lane, T., Flam, B., Lockey, R., Kolliputi, N., 2013. TXNIP shuttling: missing link between oxidative stress and inflammasome activation. Front Physiol 4, 50.

Lang, A.B., John Peter, A.T., Walter, P., Kornmann, B., 2015. ER-mitochondrial junctions can be bypassed by dominant mutations in the endosomal protein Vps13. J Cell Biol 210, 883-890.

Leal, N.S., Schreiner, B., Pinho, C.M., Filadi, R., Wiehager, B., Karlstrom, H., Pizzo, P., Ankarcrona, M., 2016. Mitofusin-2 knockdown increases ER-mitochondria contact and decreases amyloid betapeptide production. J Cell Mol Med 20, 1686-1695.

Lee, G.S., Subramanian, N., Kim, A.I., Aksentijevich, I., Goldbach-Mansky, R., Sacks, D.B., Germain, R.N., Kastner, D.L., Chae, J.J., 2012. The calcium-sensing receptor regulates the NLRP3 inflammasome through Ca2+ and cAMP. Nature 492, 123-127.

Lerner, A.G., Upton, J.P., Praveen, P.V., Ghosh, R., Nakagawa, Y., Igbaria, A., Shen, S., Nguyen, V., Backes, B.J., Heiman, M., Heintz, N., Greengard, P., Hui, S., Tang, Q., Trusina, A., Oakes, S.A., Papa, 
F.R., 2012. IRE1alpha induces thioredoxin-interacting protein to activate the NLRP3 inflammasome and promote programmed cell death under irremediable ER stress. Cell Metab 16, 250-264.

Lewis, S.C., Uchiyama, L.F., Nunnari, J., 2016. ER-mitochondria contacts couple mtDNA synthesis with mitochondrial division in human cells. Science 353, aaf5549.

Lim, Y., Cho, I.T., Schoel, L.J., Cho, G., Golden, J.A., 2015. Hereditary spastic paraplegia-linked REEP1 modulates endoplasmic reticulum/mitochondria contacts. Ann Neurol 78, 679-696.

Liu, Z., Du, X., Deng, J., Gu, M., Hu, H., Gui, M., Yin, C.C., Chang, Z., 2015. The interactions between mitochondria and sarcoplasmic reticulum and the proteome characterization of mitochondrionassociated membrane from rabbit skeletal muscle. Proteomics 15, 2701-2704.

Logan, C.V., Szabadkai, G., Sharpe, J.A., Parry, D.A., Torelli, S., Childs, A.M., Kriek, M., Phadke, R., Johnson, C.A., Roberts, N.Y., Bonthron, D.T., Pysden, K.A., Whyte, T., Munteanu, I., Foley, A.R., Wheway, G., Szymanska, K., Natarajan, S., Abdelhamed, Z.A., Morgan, J.E., Roper, H., Santen, G.W., Niks, E.H., van der Pol, W.L., Lindhout, D., Raffaello, A., De Stefani, D., den Dunnen, J.T., Sun, Y., Ginjaar, I., Sewry, C.A., Hurles, M., Rizzuto, R., Consortium, U.K., Duchen, M.R., Muntoni, F., Sheridan, E., 2014. Loss-of-function mutations in MICU1 cause a brain and muscle disorder linked to primary alterations in mitochondrial calcium signaling. Nat Genet 46, 188-193.

Lynes, E.M., Bui, M., Yap, M.C., Benson, M.D., Schneider, B., Ellgaard, L., Berthiaume, L.G., Simmen, T., 2012. Palmitoylated TMX and calnexin target to the mitochondria-associated membrane. EMBO J 31, 457-470.

Malhotra, S., Rio, J., Urcelay, E., Nurtdinov, R., Bustamante, M.F., Fernandez, O., Oliver, B., Zettl, U., Brassat, D., Killestein, J., Lechner-Scott, J., Drulovic, J., Chan, A., Martinelli-Boneschi, F., GarciaMerino, A., Montalban, X., Comabella, M., 2015. NLRP3 inflammasome is associated with the response to IFN-beta in patients with multiple sclerosis. Brain 138, 644-652.

Marini, E.S., Giampietri, C., Petrungaro, S., Conti, S., Filippini, A., Scorrano, L., Ziparo, E., 2015. The endogenous caspase-8 inhibitor c-FLIPL regulates ER morphology and crosstalk with mitochondria. Cell Death Differ 22, 1131-1143.

McGeer, E.G., McGeer, P.L., 2007. The role of anti-inflammatory agents in Parkinson's disease. CNS Drugs 21, 789-797.

Menu, P., Mayor, A., Zhou, R., Tardivel, A., Ichijo, H., Mori, K., Tschopp, J., 2012. ER stress activates the NLRP3 inflammasome via an UPR-independent pathway. Cell Death Dis 3, e261.

Meunier, J., Hayashi, T., 2010. Sigma-1 receptors regulate Bcl-2 expression by reactive oxygen species-dependent transcriptional regulation of nuclear factor kappaB. J Pharmacol Exp Ther 332, 388-397.

Mrak, R.E., Griffin, W.S., 2005. Glia and their cytokines in progression of neurodegeneration. Neurobiol Aging 26, 349-354.

Murakami, T., Ockinger, J., Yu, J., Byles, V., McColl, A., Hofer, A.M., Horng, T., 2012. Critical role for calcium mobilization in activation of the NLRP3 inflammasome. Proc Natl Acad Sci U S A 109, 1128211287.

Murley, A., Lackner, L.L., Osman, C., West, M., Voeltz, G.K., Walter, P., Nunnari, J., 2013. ERassociated mitochondrial division links the distribution of mitochondria and mitochondrial DNA in yeast. Elife 2, e00422.

Murphy, E., Pan, X., Nguyen, T., Liu, J., Holmstrom, K.M., Finkel, T., 2014. Unresolved questions from the analysis of mice lacking MCU expression. Biochem Biophys Res Commun 449, 384-385.

Naj, A.C., Schellenberg, G.D., Alzheimer's Disease Genetics, C., 2017. Genomic variants, genes, and pathways of Alzheimer's disease: An overview. Am J Med Genet B Neuropsychiatr Genet 174, 5-26.

Naon, D., Zaninello, M., Giacomello, M., Varanita, T., Grespi, F., Lakshminaranayan, S., Serafini, A., Semenzato, M., Herkenne, S., Hernandez-Alvarez, M.I., Zorzano, A., De Stefani, D., Dorn, G.W., 2nd, Scorrano, L., 2016. Critical reappraisal confirms that Mitofusin 2 is an endoplasmic reticulummitochondria tether. Proc Natl Acad Sci U S A 113, 11249-11254.

Oslowski, C.M., Hara, T., O'Sullivan-Murphy, B., Kanekura, K., Lu, S., Hara, M., Ishigaki, S., Zhu, L.J., Hayashi, E., Hui, S.T., Greiner, D., Kaufman, R.J., Bortell, R., Urano, F., 2012. Thioredoxin-interacting 
protein mediates ER stress-induced beta cell death through initiation of the inflammasome. Cell Metab 16, 265-273.

Ottolini, D., Cali, T., Negro, A., Brini, M., 2013. The Parkinson disease-related protein DJ-1 counteracts mitochondrial impairment induced by the tumour suppressor protein p53 by enhancing endoplasmic reticulum-mitochondria tethering. Hum Mol Genet 22, 2152-2168.

Pan, X., Liu, J., Nguyen, T., Liu, C., Sun, J., Teng, Y., Fergusson, M.M., Rovira, II, Allen, M., Springer, D.A., Aponte, A.M., Gucek, M., Balaban, R.S., Murphy, E., Finkel, T., 2013. The physiological role of mitochondrial calcium revealed by mice lacking the mitochondrial calcium uniporter. Nat Cell Biol 15, 1464-1472.

Park, S., Juliana, C., Hong, S., Datta, P., Hwang, I., Fernandes-Alnemri, T., Yu, J.W., Alnemri, E.S., 2013. The mitochondrial antiviral protein MAVS associates with NLRP3 and regulates its inflammasome activity. J Immunol 191, 4358-4366.

Park, S., Won, J.H., Hwang, I., Hong, S., Lee, H.K., Yu, J.W., 2015. Defective mitochondrial fission augments NLRP3 inflammasome activation. Sci Rep 5, 15489.

Pickrell, A.M., Youle, R.J., 2015. The roles of PINK1, parkin, and mitochondrial fidelity in Parkinson's disease. Neuron 85, 257-273.

Pla-Martin, D., Rueda, C.B., Estela, A., Sanchez-Piris, M., Gonzalez-Sanchez, P., Traba, J., de la Fuente, S., Scorrano, L., Renau-Piqueras, J., Alvarez, J., Satrustegui, J., Palau, F., 2013. Silencing of the Charcot-Marie-Tooth disease-associated gene GDAP1 induces abnormal mitochondrial distribution and affects Ca2+ homeostasis by reducing store-operated Ca2+ entry. Neurobiol Dis 55, 140-151.

Poston, C.N., Krishnan, S.C., Bazemore-Walker, C.R., 2013. In-depth proteomic analysis of mammalian mitochondria-associated membranes (MAM). J Proteomics 79, 219-230.

Prudent, J., Popgeorgiev, N., Bonneau, B., Thibaut, J., Gadet, R., Lopez, J., Gonzalo, P., Rimokh, R., Manon, S., Houart, C., Herbomel, P., Aouacheria, A., Gillet, G., 2013. Bcl-wav and the mitochondrial calcium uniporter drive gastrula morphogenesis in zebrafish. Nat Commun 4, 2330.

Querfurth, H.W., LaFerla, F.M., 2010. Alzheimer's disease. N Engl J Med 362, 329-344.

Rapizzi, E., Pinton, P., Szabadkai, G., Wieckowski, M.R., Vandecasteele, G., Baird, G., Tuft, R.A., Fogarty, K.E., Rizzuto, R., 2002. Recombinant expression of the voltage-dependent anion channel enhances the transfer of Ca2+ microdomains to mitochondria. J Cell Biol 159, 613-624.

Raturi, A., Simmen, T., 2013. Where the endoplasmic reticulum and the mitochondrion tie the knot: the mitochondria-associated membrane (MAM). Biochim Biophys Acta 1833, 213-224.

Rizzuto, R., Brini, M., Murgia, M., Pozzan, T., 1993. Microdomains with high Ca2+ close to IP3sensitive channels that are sensed by neighboring mitochondria. Science 262, 744-747.

Rizzuto, R., Pinton, P., Carrington, W., Fay, F.S., Fogarty, K.E., Lifshitz, L.M., Tuft, R.A., Pozzan, T., 1998. Close contacts with the endoplasmic reticulum as determinants of mitochondrial $\mathrm{Ca} 2+$ responses. Science 280, 1763-1766.

Rossol, M., Pierer, M., Raulien, N., Quandt, D., Meusch, U., Rothe, K., Schubert, K., Schoneberg, T., Schaefer, M., Krugel, U., Smajilovic, S., Brauner-Osborne, H., Baerwald, C., Wagner, U., 2012. Extracellular $\mathrm{Ca} 2+$ is a danger signal activating the NLRP3 inflammasome through $\mathrm{G}$ protein-coupled calcium sensing receptors. Nat Commun 3, 1329.

Sala-Vila, A., Navarro-Lerida, I., Sanchez-Alvarez, M., Bosch, M., Calvo, C., Lopez, J.A., Calvo, E., Ferguson, C., Giacomello, M., Serafini, A., Scorrano, L., Enriquez, J.A., Balsinde, J., Parton, R.G., Vazquez, J., Pol, A., Del Pozo, M.A., 2016. Interplay between hepatic mitochondria-associated membranes, lipid metabolism and caveolin-1 in mice. Sci Rep 6, 27351.

Saotome, M., Safiulina, D., Szabadkai, G., Das, S., Fransson, A., Aspenstrom, P., Rizzuto, R., Hajnoczky, G., 2008. Bidirectional Ca2+-dependent control of mitochondrial dynamics by the Miro GTPase. Proc Natl Acad Sci U S A 105, 20728-20733.

Sarraf, S.A., Raman, M., Guarani-Pereira, V., Sowa, M.E., Huttlin, E.L., Gygi, S.P., Harper, J.W., 2013. Landscape of the PARKIN-dependent ubiquitylome in response to mitochondrial depolarization. Nature 496, 372-376.

Schneeberger, M., Dietrich, M.O., Sebastian, D., Imbernon, M., Castano, C., Garcia, A., Esteban, Y., Gonzalez-Franquesa, A., Rodriguez, I.C., Bortolozzi, A., Garcia-Roves, P.M., Gomis, R., Nogueiras, R., 
Horvath, T.L., Zorzano, A., Claret, M., 2013. Mitofusin 2 in POMC neurons connects ER stress with leptin resistance and energy imbalance. Cell 155, 172-187.

Schreiner, B., Hedskog, L., Wiehager, B., Ankarcrona, M., 2015. Amyloid-beta peptides are generated in mitochondria-associated endoplasmic reticulum membranes. J Alzheimers Dis 43, 369-374.

Schroder, K., Tschopp, J., 2010. The inflammasomes. Cell 140, 821-832.

Shim, S.H., Xia, C., Zhong, G., Babcock, H.P., Vaughan, J.C., Huang, B., Wang, X., Xu, C., Bi, G.Q., Zhuang, X., 2012. Super-resolution fluorescence imaging of organelles in live cells with photoswitchable membrane probes. Proc Natl Acad Sci U S A 109, 13978-13983.

Shimada, K., Crother, T.R., Karlin, J., Dagvadorj, J., Chiba, N., Chen, S., Ramanujan, V.K., Wolf, A.J., Vergnes, L., Ojcius, D.M., Rentsendorj, A., Vargas, M., Guerrero, C., Wang, Y., Fitzgerald, K.A., Underhill, D.M., Town, T., Arditi, M., 2012. Oxidized mitochondrial DNA activates the NLRP3 inflammasome during apoptosis. Immunity 36, 401-414.

Simmen, T., Aslan, J.E., Blagoveshchenskaya, A.D., Thomas, L., Wan, L., Xiang, Y., Feliciangeli, S.F., Hung, C.H., Crump, C.M., Thomas, G., 2005. PACS-2 controls endoplasmic reticulum-mitochondria communication and Bid-mediated apoptosis. EMBO J 24, 717-729.

Simmen, T., Lynes, E.M., Gesson, K., Thomas, G., 2010. Oxidative protein folding in the endoplasmic reticulum: tight links to the mitochondria-associated membrane (MAM). Biochim Biophys Acta 1798, $1465-1473$.

Sood, A., Jeyaraju, D.V., Prudent, J., Caron, A., Lemieux, P., McBride, H.M., Laplante, M., Toth, K., Pellegrini, L., 2014. A Mitofusin-2-dependent inactivating cleavage of Opa1 links changes in mitochondria cristae and ER contacts in the postprandial liver. Proc Natl Acad Sci U S A.

Stoica, R., De Vos, K.J., Paillusson, S., Mueller, S., Sancho, R.M., Lau, K.F., Vizcay-Barrena, G., Lin, W.L., Xu, Y.F., Lewis, J., Dickson, D.W., Petrucelli, L., Mitchell, J.C., Shaw, C.E., Miller, C.C., 2014. ERmitochondria associations are regulated by the VAPB-PTPIP51 interaction and are disrupted by ALS/FTD-associated TDP-43. Nat Commun 5, 3996.

Stoica, R., Paillusson, S., Gomez-Suaga, P., Mitchell, J.C., Lau, D.H., Gray, E.H., Sancho, R.M., VizcayBarrena, G., De Vos, K.J., Shaw, C.E., Hanger, D.P., Noble, W., Miller, C.C., 2016. ALS/FTD-associated FUS activates GSK-3beta to disrupt the VAPB-PTPIP51 interaction and ER-mitochondria associations. EMBO Rep 17, 1326-1342.

Stone, S.J., Levin, M.C., Zhou, P., Han, J., Walther, T.C., Farese, R.V., Jr., 2009. The endoplasmic reticulum enzyme DGAT2 is found in mitochondria-associated membranes and has a mitochondrial targeting signal that promotes its association with mitochondria. J Biol Chem 284, 5352-5361.

Subramanian, N., Natarajan, K., Clatworthy, M.R., Wang, Z., Germain, R.N., 2013. The adaptor MAVS promotes NLRP3 mitochondrial localization and inflammasome activation. Cell 153, 348-361.

Szabadkai, G., Bianchi, K., Varnai, P., De Stefani, D., Wieckowski, M.R., Cavagna, D., Nagy, A.I., Balla, T., Rizzuto, R., 2006. Chaperone-mediated coupling of endoplasmic reticulum and mitochondrial Ca2+ channels. J Cell Biol 175, 901-911.

Tambini, M.D., Pera, M., Kanter, E., Yang, H., Guardia-Laguarta, C., Holtzman, D., Sulzer, D., AreaGomez, E., Schon, E.A., 2016. ApoE4 upregulates the activity of mitochondria-associated ER membranes. EMBO Rep 17, 27-36.

Triantafilou, K., Hughes, T.R., Triantafilou, M., Morgan, B.P., 2013. The complement membrane attack complex triggers intracellular Ca2+ fluxes leading to NLRP3 inflammasome activation. J Cell Sci 126, 2903-2913.

van der Laan, M., Horvath, S.E., Pfanner, N., 2016. Mitochondrial contact site and cristae organizing system. Curr Opin Cell Biol 41, 33-42.

Van Laar, V.S., Roy, N., Liu, A., Rajprohat, S., Arnold, B., Dukes, A.A., Holbein, C.D., Berman, S.B., 2015. Glutamate excitotoxicity in neurons triggers mitochondrial and endoplasmic reticulum accumulation of Parkin, and, in the presence of $\mathrm{N}$-acetyl cysteine, mitophagy. Neurobiol Dis 74, 180193.

Vance, J.E., 1990. Phospholipid synthesis in a membrane fraction associated with mitochondria. J Biol Chem 265, 7248-7256. 
Vance, J.E., 2014. MAM (mitochondria-associated membranes) in mammalian cells: lipids and beyond. Biochim Biophys Acta 1841, 595-609.

Verfaillie, T., Rubio, N., Garg, A.D., Bultynck, G., Rizzuto, R., Decuypere, J.P., Piette, J., Linehan, C., Gupta, S., Samali, A., Agostinis, P., 2012. PERK is required at the ER-mitochondrial contact sites to convey apoptosis after ROS-based ER stress. Cell Death Differ 19, 1880-1891.

Vervliet, T., Parys, J.B., Bultynck, G., 2016. Bcl-2 proteins and calcium signaling: complexity beneath the surface. Oncogene 35, 5079-5092.

Wang, P.T., Garcin, P.O., Fu, M., Masoudi, M., St-Pierre, P., Pante, N., Nabi, I.R., 2015. Distinct mechanisms controlling rough and smooth endoplasmic reticulum-mitochondria contacts. J Cell Sci.

Wang, X., Jiang, W., Yan, Y., Gong, T., Han, J., Tian, Z., Zhou, R., 2014. RNA viruses promote activation of the NLRP3 inflammasome through a RIP1-RIP3-DRP1 signaling pathway. Nat Immunol 15, 11261133.

Wieckowski, M.R., Giorgi, C., Lebiedzinska, M., Duszynski, J., Pinton, P., 2009. Isolation of mitochondria-associated membranes and mitochondria from animal tissues and cells. Nat Protoc 4, 1582-1590.

Yan, Y., Jiang, W., Liu, L., Wang, X., Ding, C., Tian, Z., Zhou, R., 2015. Dopamine controls systemic inflammation through inhibition of NLRP3 inflammasome. Cell 160, 62-73.

Yang, J., Vais, H., Gu, W., Foskett, J.K., 2016. Biphasic regulation of InsP3 receptor gating by dual Ca2+ release channel BH3-like domains mediates Bcl-xL control of cell viability. Proc Natl Acad Sci U S A 113, E1953-1962.

Yang, J.Y., Yang, W.Y., 2013. Bit-by-bit autophagic removal of parkin-labelled mitochondria. Nat Commun 4, 2428.

Yi, M., Weaver, D., Hajnoczky, G., 2004. Control of mitochondrial motility and distribution by the calcium signal: a homeostatic circuit. J Cell Biol 167, 661-672.

Zampese, E., Fasolato, C., Kipanyula, M.J., Bortolozzi, M., Pozzan, T., Pizzo, P., 2011. Presenilin 2 modulates endoplasmic reticulum (ER)-mitochondria interactions and $\mathrm{Ca} 2+$ cross-talk. Proc Natl Acad Sci U S A 108, 2777-2782.

Zheng, L., Bernard-Marissal, N., Moullan, N., D'Amico, D., Auwerx, J., Moore, D.J., Knott, G., Aebischer, P., Schneider, B.L., 2017. Parkin functionally interacts with PGC-1alpha to preserve mitochondria and protect dopaminergic neurons. Hum Mol Genet.

Zhong, Z., Umemura, A., Sanchez-Lopez, E., Liang, S., Shalapour, S., Wong, J., He, F., Boassa, D., Perkins, G., Ali, S.R., McGeough, M.D., Ellisman, M.H., Seki, E., Gustafsson, A.B., Hoffman, H.M., DiazMeco, M.T., Moscat, J., Karin, M., 2016. NF-kappaB Restricts Inflammasome Activation via Elimination of Damaged Mitochondria. Cell 164, 896-910.

Zhou, R., Tardivel, A., Thorens, B., Choi, I., Tschopp, J., 2010. Thioredoxin-interacting protein links oxidative stress to inflammasome activation. Nat Immunol 11, 136-140.

Zhou, R., Yazdi, A.S., Menu, P., Tschopp, J., 2011. A role for mitochondria in NLRP3 inflammasome activation. Nature 469, 221-225.

Zufiria, M., Gil-Bea, F.J., Fernandez-Torron, R., Poza, J.J., Munoz-Blanco, J.L., Rojas-Garcia, R., Riancho, J., de Munain, A.L., 2016. ALS: A bucket of genes, environment, metabolism and unknown ingredients. Prog Neurobiol 142, 104-129. 


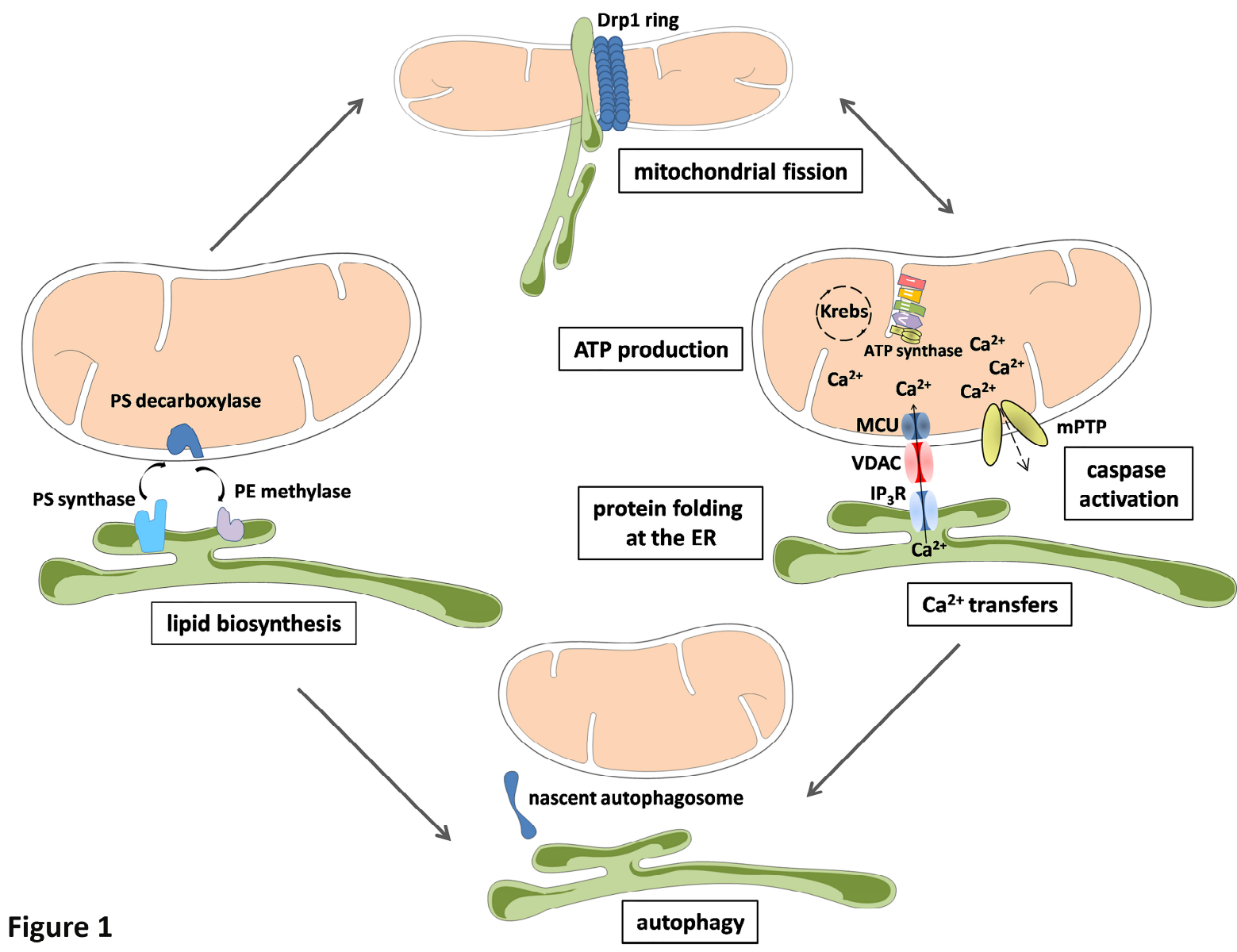




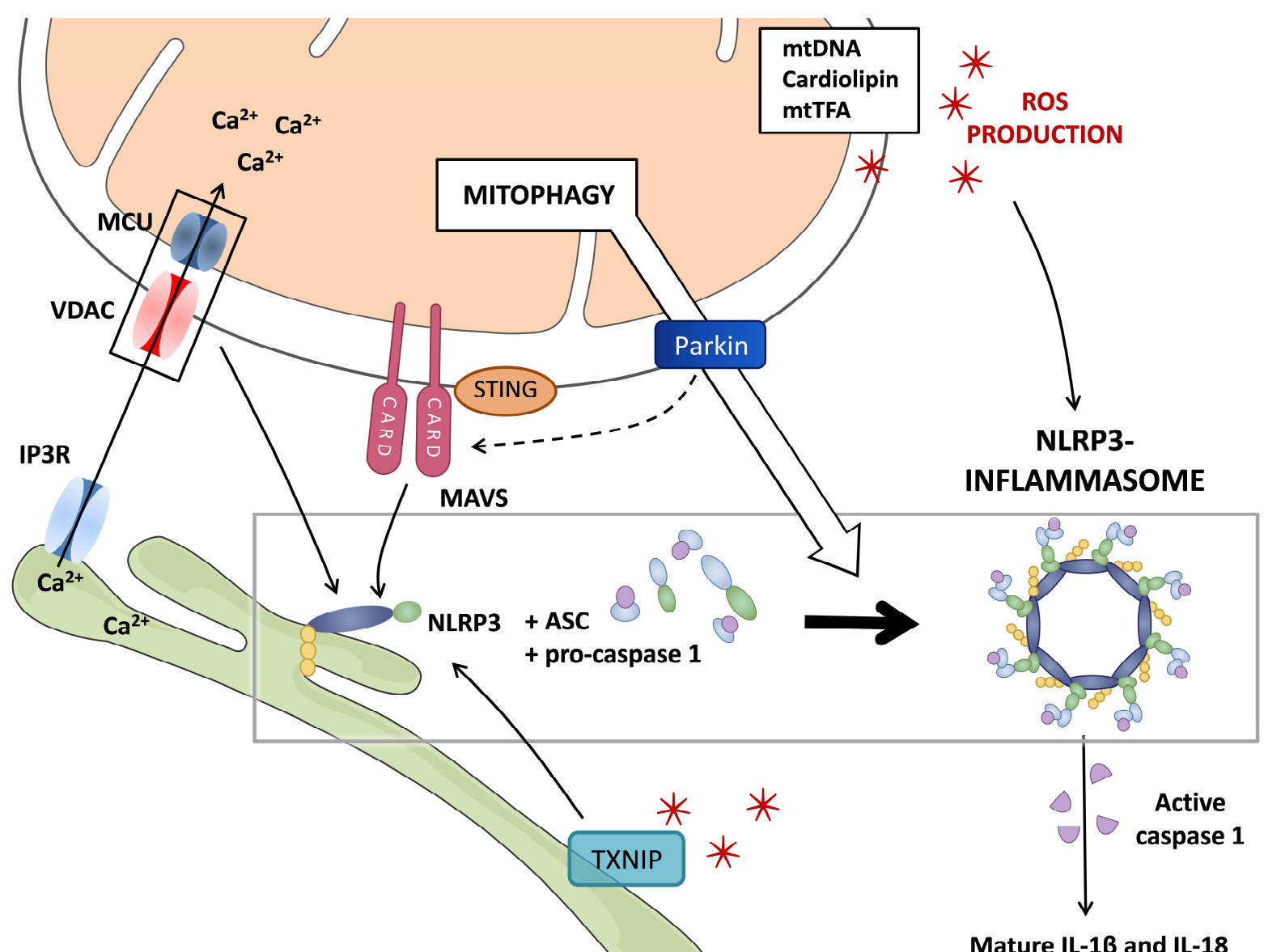

Figure 2

Mature IL-1 $\beta$ and IL-18 


\section{neurodegeneration}

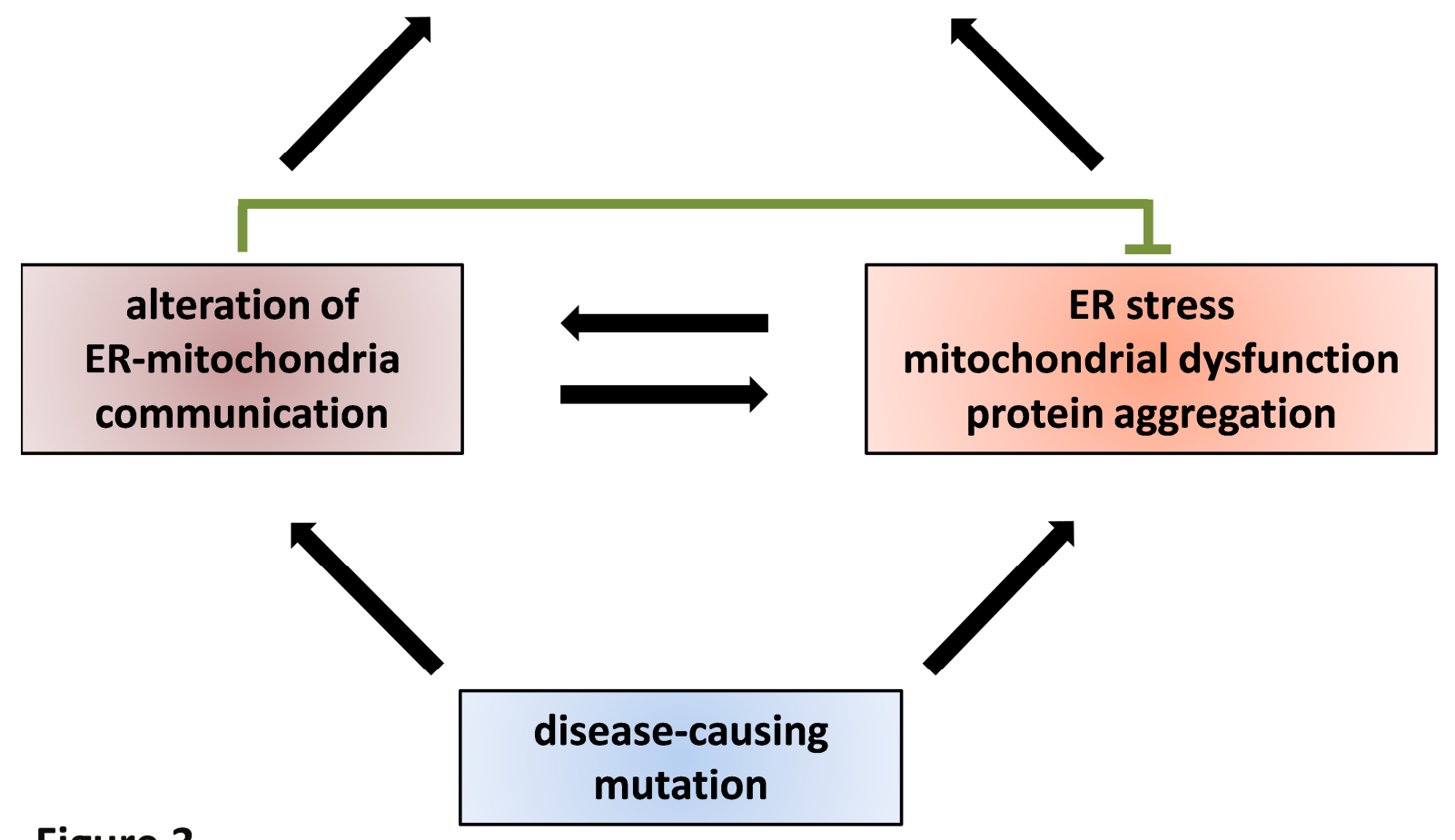

Figure 3 


\title{
From dysfunctional endoplasmic reticulum-mitochondria coupling to neurodegeneration
}

\author{
Zoi Erpapazoglou ${ }^{1-4}$, François Mouton-Liger ${ }^{1-4}$, and Olga Corti ${ }^{1-4}{ }^{*}$ \\ ${ }^{1}$ Inserm, U1127, F-75013, Paris, France \\ ${ }^{2}$ CNRS, UMR 7225, F-75013, Paris, France \\ ${ }^{3}$ Sorbonne Universités, UPMC Univ Paris 06, UMR S 1127, F-75013, Paris, France \\ ${ }^{4}$ Institut du Cerveau et de la Moelle épinière, ICM, F-75013, Paris, France \\ *corresponding author: olga.corti@upmc.fr, +33157274651
}

\section{Highlights:}

- The ER-mitochondria interface is a versatile and multitasking subcellular platform involved in metabolism, membrane dynamics and signaling

- Structural and functional defects of the ER-mitochondria interface are observed in neurodegenerative diseases

- Defects in ER-mitochondria communication may reflect primary mechanisms, side-effects or compensatory responses to disease-causing mutations

- Combination of models and methodologies will help bypassing current limitations in the study of ER-mitochondria contact sites 